LA-UR-95- 692

ттाе: Cost Effectiveness Studies of Environmental Technologies: Volume I

$\begin{array}{ll}\text { EDITOR(S): } & \text { E. Michelle Silva, TSA-4 } \\ \text { Steven R. Booth, TSA-4 }\end{array}$

SUBMITED TO: $\quad$ General Distribution, February 1994
RECEIVEO

MAR 101995

OSTI

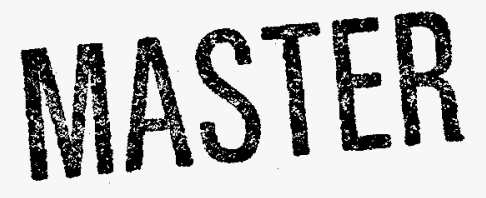

By acceptance of this article, the publisher recognized that the U S Government retains a nonexclusive, royalty-free license to publish or reproduce the published form of this contribution of to allow others to do so for $U S$ Government purposes.

The Los Alamos National Laboratory requests that the publisher identity this article as work performed under the auspices of the U S Department of Energy.

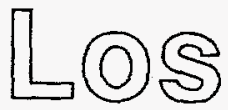

AlamoS

Los Alamos National Laboratory
Los Alamos, New Mexico 87545 


\section{DISCLAIMER}

This report was prepared as an account of work sponsored by an agency of the United States Government. Neither the United States Government nor any agency thereof, nor any of their employees, make any warranty, express or implied, or assumes any legal liability or responsibility for the accuracy, completeness, or usefulness of any information, apparatus, product, or process disclosed, or represents that its use would not infringe privately owned rights. Reference herein to any specific commercial product, process, or service by trade name, trademark, manufacturer, or otherwise does not necessarily constitute or imply its endorsement, recommendation, or favoring by the United States Government or any agency thereof. The views and opinions of authors expressed herein do not necessarily state or reflect those of the United States Government or any agency thereof. 


\section{DISCLAIMER}

Portions of this document may be illegible in electronic image products. Images are produced from the best available original document. 
In Situ Air Stripping Performance Cases vs Conventional

Technologies (5 year life cycle)

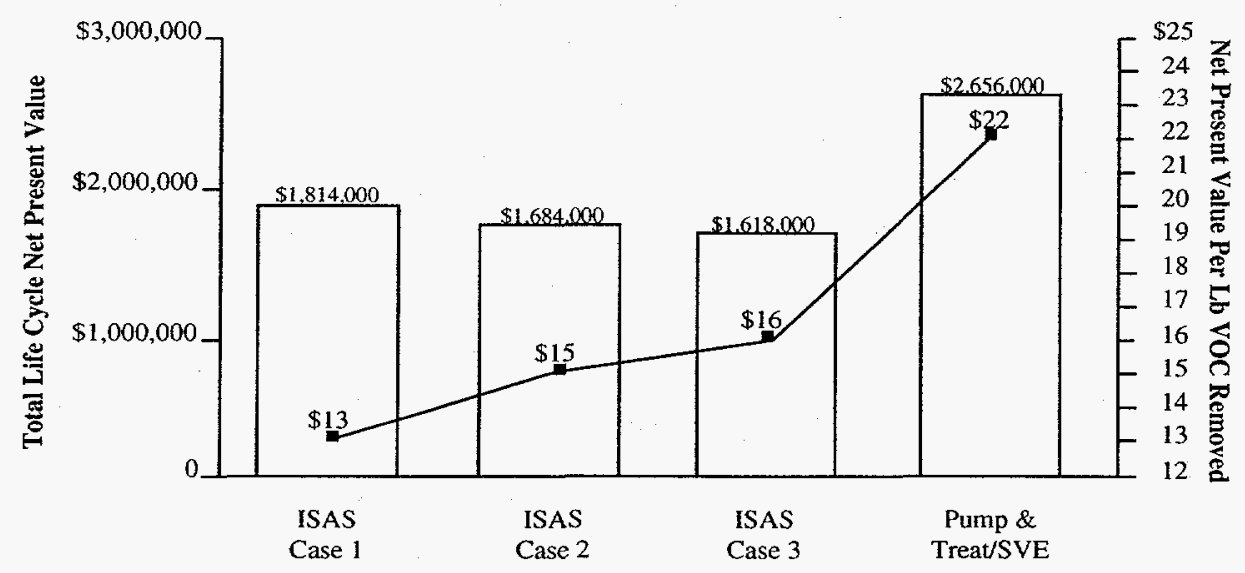

\title{
Cost Effectiveness Studies of Environmental Technologies: Volume I
}

\author{
Environmental Technology Cost-Savings \\ Analysis Project (ETCAP)
}

sponsored by the

Office of Technology Development,

Department of Energy

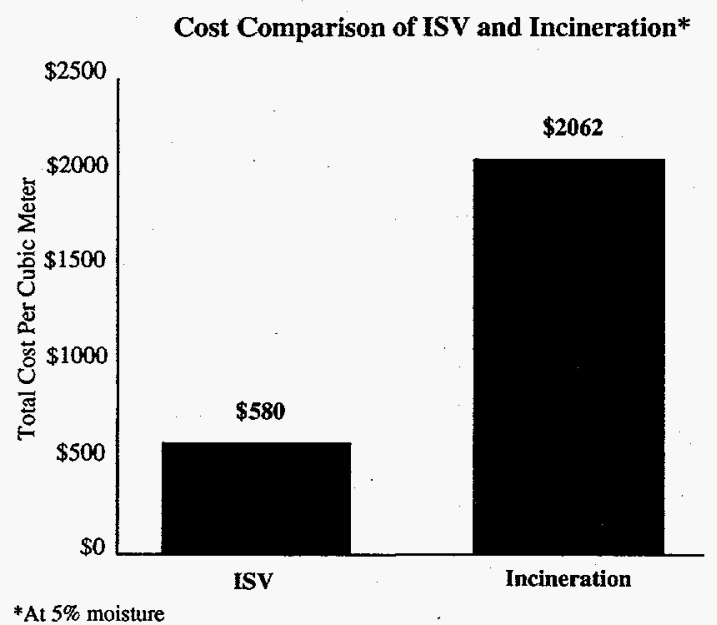

Cost Drivers of Ditch Witch Technology

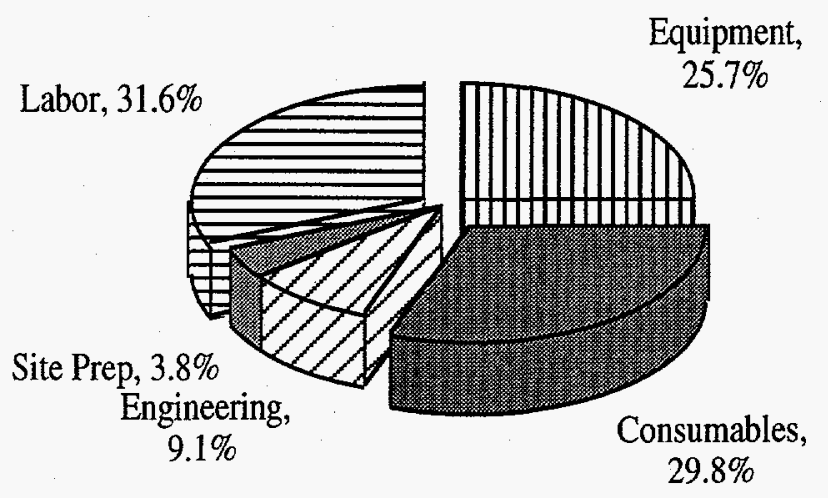




\section{Table of Contents}

Title

Page

In Situ Air Stripping

Surface Towed Ordinance Locator System

Ditch Witch ${ }^{\mathrm{TM}}$ Horizontal Boring Technology

Direct Sampling Ion Trap Mass Spectrometer

In Situ Vitrification

Site Characterization and Analysis Penetrometer System

In Situ Bioremediation

30

SEAMIST ${ }^{\mathrm{TM}}$ Membrane System Technology

36 


\section{In Situ Air Stripping}

- In Situ Air Stripping (ISAS) is estimated to remediate both the vadose zone and saturated zone (groundwater and sediments below the water table) contaminated with chlorinated solvents for two-thirds the cost of conventional methods

- ISAS can remove VOCs for approximately $58 \%$ of the cost of removal by a combination of conventional pump and treat and soil vapor extraction

- ISAS removed 16,000 pounds of VOCs during a 139 day field test at the Savannah River Site in 1990

- ISAS (with a combination of injection and extraction) removes VOCs at a rate of 130 lbs/day

- The total cost per pound of VOCs removed with ISAS was $\$ 15.59$; the conventional technology cost $\$ 27.07$ per pound of VOCs removed

- Over a five year life cycle, ISAS is expected to remove 135,780 pounds of VOCs

\section{Background and Caveats}

In situ air stripping is a remediation technology that was demonstrated at the Savannah River Integrated Demonstration (SRID) test site in 1990. The demonstration used two directionally drilled horizontal wells to deliver air and extract contaminants from the subsurface. This in situ air stripping process was designed to remediate soils and sediments above and below the water table as well as groundwater, all contaminated with volatile organic compounds (VOCs).

This analysis was prepared by the Environmental Technology Cost Analysis Project (ETCAP), Los Alamos National Laboratory, and was sponsored by the Office of Technology Development, Department of Energy. The cost figures used in this analysis were obtained from actual practice.

\section{Analysis}

The data used in these analyses have a "field demonstration" level of confidence. The numbers are based on a full scale field demonstration. The performance comparison consists of Plan 1: 2 horizontal in situ air stripping wells with the extraction well having the cumulative VOC removal of 16,000 pounds, and Plan 2: 1 pump and treat well and 4 soil vapor extraction wells with the cumulative VOC removal of 13,954 . Both the pump and treat and SVE data were extrapolated to 139 days in order to create a short term field scale comparison where each system was of the same time duration. The pump and treat extrapolation (from 114 to 139 days) is a minimal extension of existing data. The SVE extrapolation (from 21 to 139 days) is based on an extraction rate of $10 \mathrm{lb} /$ day for day 21 to day 
139. This is reasonably supported by the pilot test performance.

The performance scenario comparing in situ air stripping with pump and treat/soil vapor extraction is now evaluated for costs. The first economic comparison uses performance data from actual short term field tests of each technology. The equipment capital costs are annualized over the useful life of the equipment, which is assumed to be 10 years. The total site costs for in situ air stripping alone (Plan 1) are $\$ 249,518$. The total cost per lb of VOCs removed is $\$ 15.59$. Total site costs for pump and treat/soil vapor extraction (Plan 2) are $\$ 377,722$. The total cost per $\mathrm{lb}$ of VOCs removed is $\$ 27.07$. This comparison shows that ISAS can remove VOCs for $58 \%$ of the cost of removal by a combination of the two conventional technologies.
The second economic comparison uses estimated performance curves for the reduction in rate of contaminant removal with each technology to determine life cycle costs for a remediation time scale of 5 years. Life cycle costs are generated that reflect the true life time costs of operation for the remediation system: capital costs, ongoing monitoring costs, operation and maintenance costs, etc. The net present value for Plan 1 is $\$ 1,814,000$. A total of $135,780 \mathrm{lbs}$ VOCs is estimated to be removed over the five year operation of ISAS. The net present value of Plan 2 is $\$ 2,656,000$. A total of $121,545 \mathrm{lbs}$ VOCs is estimated to be removed over the five year operation of the conventional technologies. This comparison indicates that 5 year operation of ISAS can remove VOCs from soils and groundwater for $60 \%$ of the cost of removal by conventional alternatives.

\section{In Situ Air Stripping Performance Cases vs Conventional Technologies (5 year life cycle)}

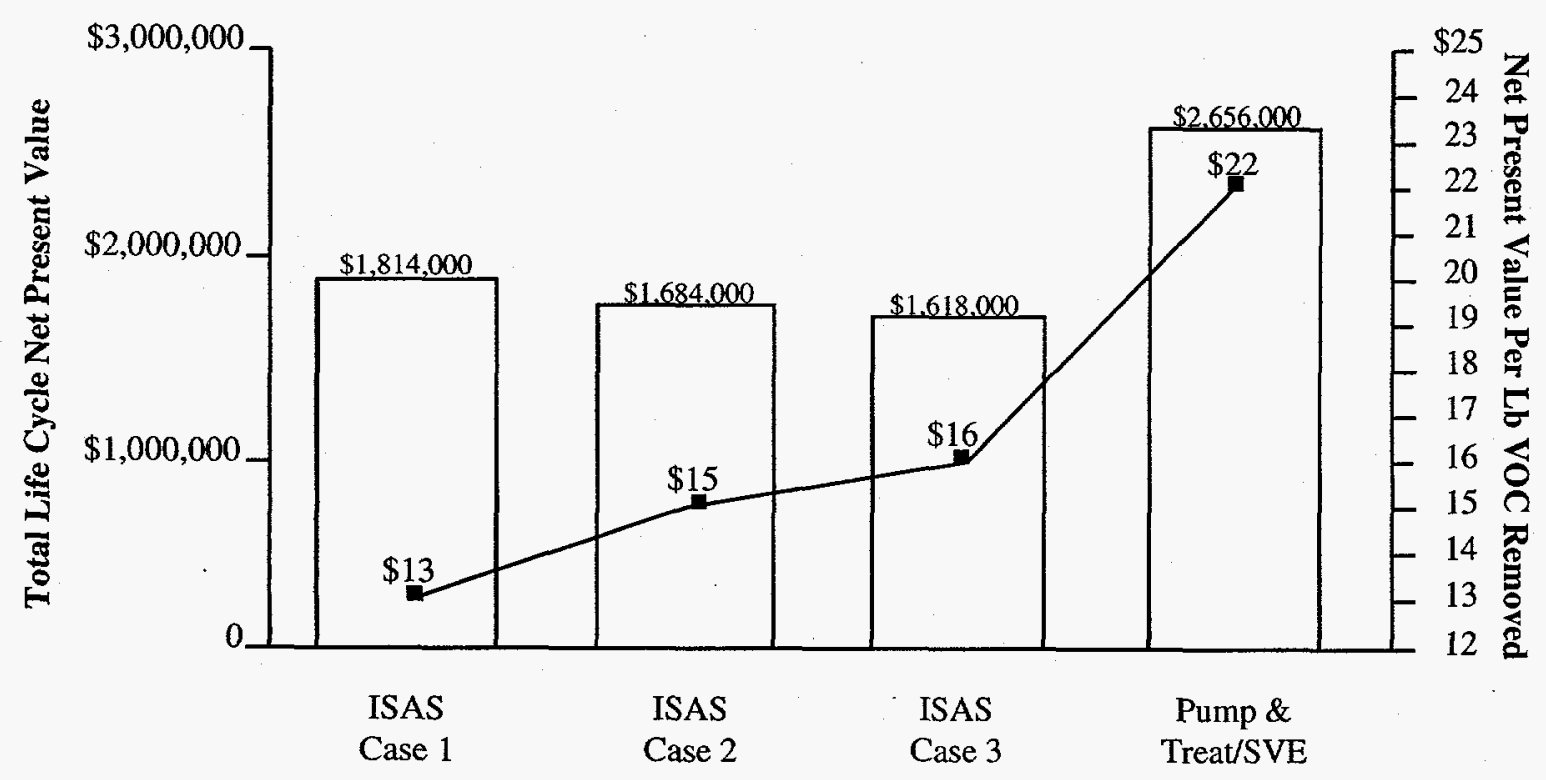


Because the 5 year performance of ISAS is not known, several different simple estimates of the ISAS VOC extraction rate over time are considered. Case 1 is the same performance curve used above. Cases 2 and 3 illustrate performance curves worse than Case 1 . In Case 2 we assume that the first year ISAS VOC extraction rate averages only $86 \mathrm{lb} /$ day. Case 2 assumes a $50 \%$ reduction of the demonstration rate for years 2 through 5. In Case 3 we assume that the ISAS VOC extraction rate is only $57 \mathrm{lb} /$ day for the entire 5 years.

The cost comparisons indicate that even if ISAS performance is significantly worse than estimated in Case 1, ISAS remains cost effective relative to the conventional technologies. Note that ISAS Case 3 is still clearly cost effective relative to the conventional technology.

\section{Perspectives and Cost Drivers}

The most expensive component of the ISAS system is the cost of consumables. This includes the fuel and maintenance supplies. The cost of the carbon recharge at $\$ 101,688(\$ 2.23 \mathrm{lb}$ carbon/lb VOC) contributes significantly to the total cost of consumables at $\$ 157,761$. This cost occurs each year of operation. The following figure shows the percentage of each cost component. It is important to note that these cost data are based on estimates; therefore, ranges of uncertainties were not considered in this costeffectiveness analysis because actual cost data were available.

Compared to the conventional technologies, a pump and treat/soil vapor extraction combination, ISAS is still less expensive in terms of the cost of consumables. ISAS has a total cost of

\section{ISAS Short-term Costs}

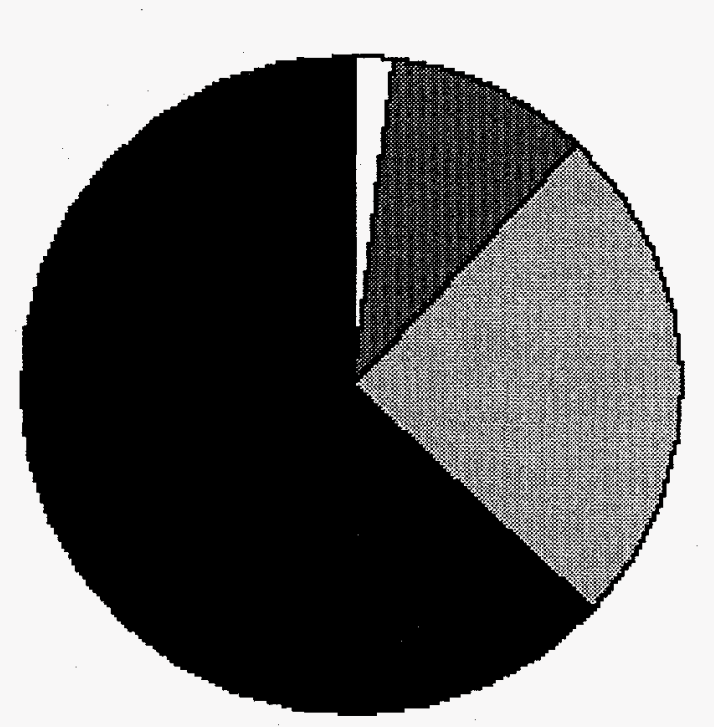

Consumable cost $63 \%$

Labor Costs $25 \%$

Annualized Equipment Costs $10 \%$

Site costs $2 \%$ 
consumables of $\$ 157,761$. Pump and treat/soil vapor extraction has a total consumable cost of $\$ 221,265$. ISAS represents a $29 \%$ savings even in cost of consumables.

\section{Applicability}

Successful in situ air stripping requires good contact between the injected air and contaminated soils and groundwater. As such, the optimum geologic setting has the following characteristics: moderate to high saturated soil permeability, a homogeneous saturated zone, and sufficient saturated thickness. Similarly, optimum characteristics for the vadose zone are high permeability and homogeneity. Air sparging is generally more effective in coarse-grained soil. Clay layers, because of their low permeability, are problematic. The results of the SRID in situ air stripping demonstration, however, indicate that ISAS can be effective in settings where some interbedded thin and/or discontinuous clays are present.

\section{References}

Schroeder, J.D., R.D. Rosenberg, E.P. BarnesSmith, and S.R. Booth, "In Situ Air Stripping: Cost Effectiveness of a Remediation Technology Field Tested at the Savannah River Integrated Demonstration Site," Los Alamos National Laboratory report No. LA-UR-92-1927 (June 1992).

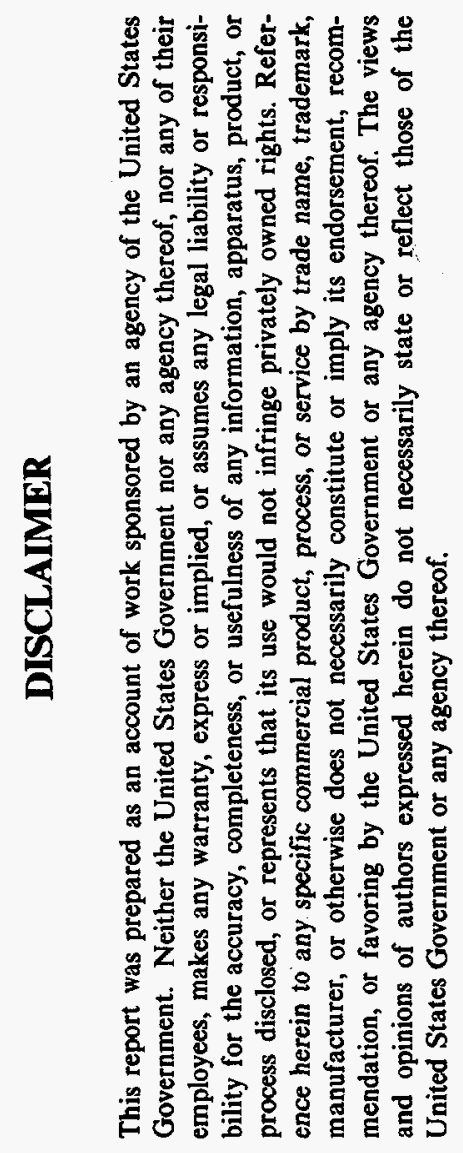




\section{Surface Towed Ordinance Locator System (STOLS)}

- STOLS is being developed as a faster, more accurate means of performing magnetometer surveys of a site.

- The primary use for STOLS is in finding low magnetic signature objects relatively close to the surface.

- For more hazardous environments, STOLS provides the surveyors with less danger.

- For a DOE waste site requiring $5 \mathrm{ft}$. centers, STOLS does not become cost effective until high labor rates and/or at least 50 acres are to be surveyed.

\section{Background and Analysis}

STOLS is being developed as a faster, more accurate means of performing magnetometer surveys of a site. It is a ruggedized, off-road vehicular based system complete with a portable adjunct for areas which are non-vehicular navigable. Physically the STOLS system contains an off-road vehicle, similar in appearance to a dune buggy, which tows a trailer. Mounted on the trailer, in a line perpendicular to the line of travel, are the seven magnetometers mounted with a spacing of $1.5 \mathrm{ft}$. Mounted in the tow vehicle is a GPS transponder system, as well as the data capture and display equipment.

The STOLS man-portable device contains two magnetometers spaced 1.5 feet apart, a data cap- ture system, and GPS transponder system. The two magnetometers are mounted on arms that protrude to the front of the person carrying the device, while the other electronics are mounted on the back of the person carrying the system. The two parts of the system are connected using a rigid cage that wraps over the shoulders of the carrier. The effective grid size of this system is comparable to the towed device, but is dependent upon the speed at which the carrier walks and the data capture rate of the device. While no specific values for these two parameters were given by Geo-Centers, it is possible to gain an approximate estimate of the actual grid size and yield in data points per acre.

\section{Perspectives}

In this section, we address some of the differences in performance between the STOLS system and conventional hand-held magnetometer surveys. Both methods provide a way of collecting information about the subsurface geology, with emphasis placed on locating buried man-made objects. In a hand-held magnetometer survey, a site is divided into convenient areas of about 1 acre each. The boundary of each area is defined in terms of latitude and longitude reference points, usually at the corners. A grid is laid out in the area, where typical grid sizes are five foot squares (also known as five foot centers) or two foot squares (two foot centers). This yields a typical total of 1,760 points or 10,890 points per acre, respectively, for the 
five foot and two foot resolution grids, where one acre is $43,560 \mathrm{sq}$. $\mathrm{ft}$, and a typical acre would measure $220 \mathrm{ft}$. by $198 \mathrm{ft}$.

The STOLS towed system is capable of providing 72,600 or more data points per acre in its normal operation, for a typical acre. The STOLS man-portable system is capable of providing 193,600 or more data points per acre in its normal operation, for a typical acre. Thus STOLS provides higher resolution than the baseline. STOLS requires no preliminary survey to create a grid where data points are to be taken. Rather, STOLS uses the Global Positioning Satellite (GPS) system to associate latitude and longitude information with each data point.

In comparing the performance of STOLS and the baseline technology, we focus on the intended use of STOLS: the replacement, wherever reasonable, of hand-held conventional magnetometer surveys. Thus, we will consider the strategies for performing a magnetometer sur- vey as listed the following table.

In order to consider a broad range of possible STOLS applications, scenarios are constructed that are directly related to the plans given in the table. The first scenario compares the cost of using STOLS (Plans 3 and 4) with the cost of using on-site personnel and equipment (Plan 1) because STOLS is a service provided by GeoCenters, Inc., and is not at this time a hardware and software system that is offered for sale. Thus, a per-acre rate can be established from information provided by Geo-Centers.. This use of on-site personnel and equipment is a key assumption that the first scenario will be predicated upon. We feel that this a reasonable assumption in that it permits the reader to determine what the approximate minimum costs should be in the absence of any overhead and profits charged by contractors that perform this type of survey. The second scenario will compare the cost of using a contractor to perform the survey in the conventional manner (Plan 2)

\section{Table: Performance Comparison Strategies}

Plan

\section{Description}

Conventional surveys only using on-site personnel and equipment

Conventional surveys only using an independent contractor

STOLS surveys only, using the most cost-effective STOLS device for the site, ideal site conditions

STOLS surveys only, using the most cost-effective STOLS device for the site, non-ideal site conditions 
with surveys performed by STOLS (Plans 3 and 4).

Additionally, each of these scenarios will be considered in conjunction with two other factors. The first factor to be varied will be a comparison made between using five foot centers versus two foot centers for the hand-held conventional survey. The second factor to be considered will be the health protection precautions required by workers at the site. For the purposes of the principal study presented here, workers at the site will be assumed to be using level D protection.

The scenarios are then analyzed for their peracre cost of performing the survey. The scenarios are not meant to be comprehensive cost estimations for site characterization using magnetometer data. Rather, we are interested in comparing the cost effectiveness of the new technology (STOLS) relative to the baseline technology.

\section{A. Comparing STOLS with Conven-} tional (On-Site Personnel)

The results of the comparison are somewhat mixed depending on the labor rate, site size, and health precautions being considered. A general conclusion is that STOLS is not cost effective for buried waste sites requiring level D precautions or lower and $5 \mathrm{ft}$. centers or larger until the total area to be surveyed reaches 50 acres and a high labor rate is used. However, there are other factors to be considered. For example, when $2 \mathrm{ft}$. centers are required, STOLS becomes cost effective between 2 and 5 acres. For even tighter grid requirements, we believe that STOLS will be cost effective for very small site sizes (less than 1 acre). Grid requirements are directly related to the amount of data required to adequately characterize a given site. If the site contains only buried waste trenches and the goal of the survey is to identify those trenches, then a $5 \mathrm{ft}$. survey (or an even greater grid spacing) is sufficient and the additional data provided by STOLS is of little value. However, surveys performed at sites that contain ill-defined burial locations, or at sites where characterization is important, or when time is critical, would benefit from the added information and/or speed available when employing STOLS.

\section{B. Comparing STOLS with Conven-} tional (Contractor)

For the contractor prices used in this section, STOLS becomes cost effective in a variety of site size ranges. However, the reader is cautioned that all of the concerns raised in this report still need to be addressed, the principal concern being that of just how much data is needed to adequately characterize the site. Since our survey indicates that the average charge is approximately $\$ 2,000$ per acre for a conventional survey ( $5 \mathrm{ft}$. centers) of a site requiring level D precautions, STOLS does not become cost effective until site sizes of approximately 50 acres are reached for a typical DOE site. Similarly, since our survey gives an average charge of $\$ 2,500$ per acre for a conventional survey (again, $5 \mathrm{ft}$. centers) of a typical DOE site requiring level $\mathrm{C}$ precautions, again a site size of approximately 
50 acres must be reached before STOLS becomes a cost-effective system to employ.

\section{Cost Drivers}

The major cost drivers for the STOLS system are labor, site size, and mobilization/demobilization costs. Because Geo-Centers Inc. does not sell STOLS as a hardware and software package, the equipment must be moved from the nearest Geo-Centers Inc. center of operations to the necessary location. This can mean incurring significant additional costs that are not incurred by the baseline technology. Labor rates must also be considered as a cost driver because they vary from region to region, starting as low as $\$ 40$ per hour and reaching higher than $\$ 80$ an hour. If STOLS is used in an area with high labor rates, then the cost of using STOLS will increase as well. Site size can also affect the total cost of using STOLS. For a small site (less than 50 acres), STOLS is not cost effective. As the size of the site increases, the cost of using STOLS decreases and becomes more effective.

\section{Applicability}

The STOLS towed device is more susceptible to terrain problems than either the STOLS portable device or the conventional device. Therefore, for sites that require any preparatory work, the models presented in this report should be updated to include the costs of this work prior to the selection of the method to employ. One conclusion that is indicated by the data is that STOLS becomes more cost effective as the hazards at the site increase. If Geo-Centers so de sires, they may be able to build a STOLS system for hazardous sites requiring level B or A precautions. At these sites, STOLS will probably be very competitive. STOLS is also desirable in sites that require the added information available from a denser survey. Thus if it is believed that there might be objects buried at a site for which there is no historical or other evidence to indicate the locations of these objects, and if these objects are small enough to be missed by a conventional survey, then the use of STOLS is warranted.

\section{Conclusions}

- When additional data density is desirable (that is, $2 \mathrm{ft}$. centers or denser is required), STOLS becomes the more cost effective choice.

- For a ten acre site, using a labor rate of $\$ 60$ / $\mathrm{hr}$ and level $\mathrm{C}$ precautions, STOLS saves $\$ 57,000$ over the same survey performed in the conventional manner.

- Although STOLS does not appear to be cost effective for small sites when compared against typical DOE magnetometer surveys, STOLS provides two orders of magnitude additional data that may set the standard for such surveys in the future.

\section{References}

Bremser, J.P. and S.R. Booth, "Cost Effectiveness of the Surface Towed Ordinance Locator System (STOLS)," Los Alamos National Laboratory report No. LA-UR-93-4396 (February 1994). 


\section{Ditch Witch ${ }^{{ }_{1}}$ Horizontal Boring Technology}

- Ditch Witch horizontal boring technology is a method of installing shallow (less than 80 $\mathrm{ft}$ ) environmental horizontal boreholes and wells in compactible geologies.

- The most significant advantage of the technology is its low cost when compared to other horizontal drilling methods and its ability to emplace wells and boreholes with little or no secondary waste generation.

- Costs for this technology normally range between \$50-\$75 per foot for installation of a horizontal well. This is significantly less than most other horizontal drilling methods.

- In situations where vertical access is limited and large volumes of drilling fluids cannot be used, this type of technology may be the only acceptable method of installing wells for characterization, monitoring, or remediation.

- For the remediation of a long, linear plume a single horizontal Soil Vapor Extraction (SVE) well can be expected to have performance and costs comparable to two or three vertical wells. In these situations consideration should be given to the practical advantages of operating and maintaining a single well over two or three manifolded wells.

\section{Analysis \& Caveats}

Ditch Witch horizontal boring technology for environmental applications resulted from an industrial partnership between Charles Machine Works (CMW) of Perry, OK and Sandia National Laboratory (SNL). This technology is a hybrid horizontal boring technology which has made use of technology from underground utilities installation, river crossing drilling, cone penetrometer site characterization, and other environmental drilling technologies. Ditch Witch equipment is intended to be used in compactible geologies with sands, clays, and gravels, at shallow depths, less than 80 feet below ground surface (bgs). It is not intended or expected to perform well in rough cobble and boulder geologies such as those encountered at Westinghouse Hanford. This equipment was designed to install shallow horizontal boreholes and wells at competitive costs. The installation process has a minimal environmental impact. The Ditch Witch method is primarily a low pressure, low volume fluid assist boring technology.

The cost-effectiveness of Ditch Witch technology is evaluated based upon its ability to economically replace existing technologies as well as its ability to drill, with little or no waste, in sites with limited vertical access. The technology can also be used in situations where a need for more screen length in the plume exists. It is important to realize that Ditch Witch equipment was designed to meet a specific range of environmental restoration needs. When used in appropriate situations within this range, Ditch Witch horizontal wells can be expected to provide cost savings over other technologies. It is important to recognize those sites, with appropriate geology and contaminant location, for which this method may be expected to work well and prove cost-effective.

\footnotetext{
${ }^{1}$ Ditch Witch is a registered trademark of the Charles MachineWorks, Inc.
} 
Cost data for the Ditch Witch technology used in this analysis are based on estimated costs of actual field experiments conducted at SNL. [Wemple facsimile 6/27/94] Individual contractors were consulted for rough cost estimates for installing specific wells via other horizontal drilling methods. Assumptions made regarding the performance and costs of horizontal vs. vertical Soil Vapor Extraction (SVE) wells are based on the numerical modeling of Birdsell et $a l$ and SVE cost analysis of Schroeder et al.

\section{Cost Drivers}

The pie chart below shows major costs of installing a horizontal well using Ditch Witch methods by percentage of total costs, which normally range between $\$ 50$ - $\$ 75$ per foot. The most significant costs of this technology are seen in Labor, Equipment, and Consumables.

It must be noted that the cost of Consumables includes the cost of materials for casing and screening of a completed well. Because Ditch Witch equipment installs the casing and screening via a pull back procedure starting at the borehole exit, in some geologies it is necessary to use relatively expensive, high quality casing materials. In cases where the Ditch Witch equipment is used only for characterization or monitoring, the percentage of total cost of Consumables is less, and the primary cost drivers are Labor and Equipment. It should also be noted that these percentages are based on cost estimates of actual wells installed by SNL and CMW. These percentages can be expected to vary somewhat in different geologic settings.

\section{Perspectives \& Calculations}

Evaluation of the cost effectiveness of Ditch Witch horizontal boring technology should consider several types of scenarios. This analysis will include scenarios for: 1) comparison of the

\section{Cost Drivers of Ditch Witch Technology}

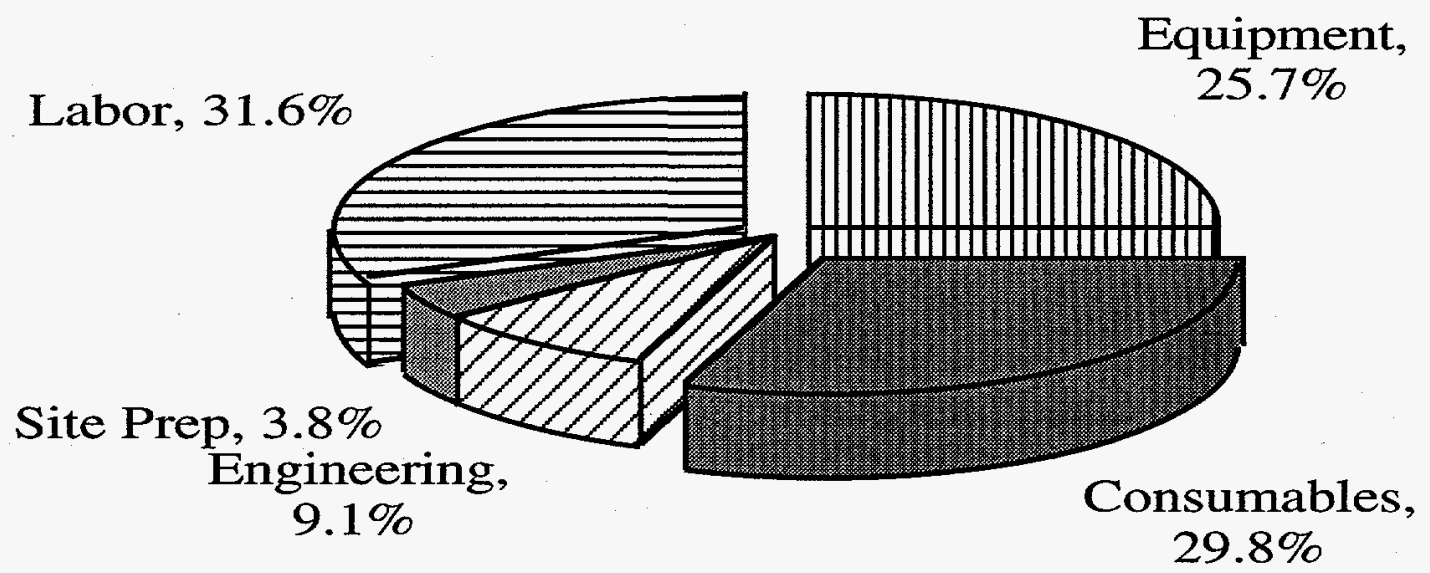


cost-effectiveness of different horizontal drilling technologies at shallow depths and 2) situations in which Ditch Witch horizontal wells are more cost-effective for the remediation of a contaminant site than either vertical wells or other horizontal installation techniques,.

In many situations vertical access to a contaminant site may be limited or non existent, such as contaminants located beneath buildings, roads, waste pits, etc. In these situations horizontal drilling is often the only means of accessing a contaminant plume for characterization, monitoring, and remediation. Most horizontal drilling methods are expensive and can be waste intensive when drilling through a contaminated region. The table below compares estimated costs of installing an SVE well with $240 \mathrm{ft}$ of a 4 in. ID screen, $30 \mathrm{ft}$ bgs. in a VOC plume.

Ditch Witch technology can be used to install this well at a much lower cost than all other methods except the UTILX fluid jet method, which costs nearly the same as Ditch Witch. Notice that Ditch Witch is the only method which does not generate waste materials. This is a very important advantage over the UTILX fluid jet, which generates large volumes of fluid waste that must be treated and/or disposed. The fluid jet also runs the risk of spreading a contaminant plume during the cutting of the borehole. Hence, in situations where environmental impact is an important consideration, Ditch Witch is the optimal choice of horizontal drilling technologies for work in shallow, compactible geologies.

Numerical simulations have shown the performance of a single SVE horizontal well to be consistently greater than the performance of a single SVE vertical well only in situations where the contaminant plume is a long, linear plume. (Birdsell et al.) Here a long, linear plume is considered to be one where the length of the plume is greater than the radius of influence of a single vertical vapor extraction well in a given

Table. A Comparison of Estimated Costs to Install an SVE Well

\begin{tabular}{|l|l|c|c|c|c|c|}
\hline $\begin{array}{l}\text { Drilling } \\
\text { Contractor }\end{array}$ & $\begin{array}{l}\text { Drilling } \\
\text { Method }\end{array}$ & $\begin{array}{c}\text { Type of } \\
\text { Well }\end{array}$ & $\begin{array}{c}\text { Total } \\
\text { Length }\end{array}$ & $\begin{array}{c}\text { Cost of Well } \\
\text { Installation }\end{array}$ & $\begin{array}{c}\text { Waste* } \\
\text { Disposal }\end{array}$ & $\begin{array}{c}\text { Total } \\
\text { Cost** }\end{array}$ \\
\hline SNL/CMW & Ditch Witch & Continuous & $385 \mathrm{ft}$ & $\$ 26,500$ & $\$ 0$ & $\$ 26,500$ \\
\hline $\begin{array}{l}\text { Eastman } \\
\text { Cherrington }\end{array}$ & $\begin{array}{l}\text { Down Hole } \\
\text { Rotary }\end{array}$ & Blind & $485 \mathrm{ft}$ & $\$ 81,600$ & $\$ 4,500$ & $\$ 86,100$ \\
\hline UTILX & Fluid Jet & Continuous & $500 \mathrm{ft}$ & $\$ 22,500$ & $\$ 4,500$ & $\$ 27,000$ \\
\hline Drilex & Rotary & Blind & $425 \mathrm{ft}$ & $\$ 115,000$ & $\$ 4,500$ & $\$ 119,500$ \\
\hline $\begin{array}{l}\text { Michels } \\
\text { Environmental }\end{array}$ & Fluid Jet & Continuous & $500 \mathrm{ft}$ & $\$ 40,000$ & $\$ 4,500$ & $\$ 44,500$ \\
\hline
\end{tabular}

* Assume hazardous waste disposal costs $\$ 600$ per 55 gallon drum. Since all methods need waste fluid treatment, except Ditch Witch technology, waste disposal costs are assumed equivalent @ \$4,500.

** Does not include Mob./Demob. To be fair, these costs are assumed equivalent, however in most cases, the Ditch Witch method requires significantly less equipment, transportation and set up time. 


\section{Costs for Operating SVE System to Remove Roughly 11,000 lbs of TCE}

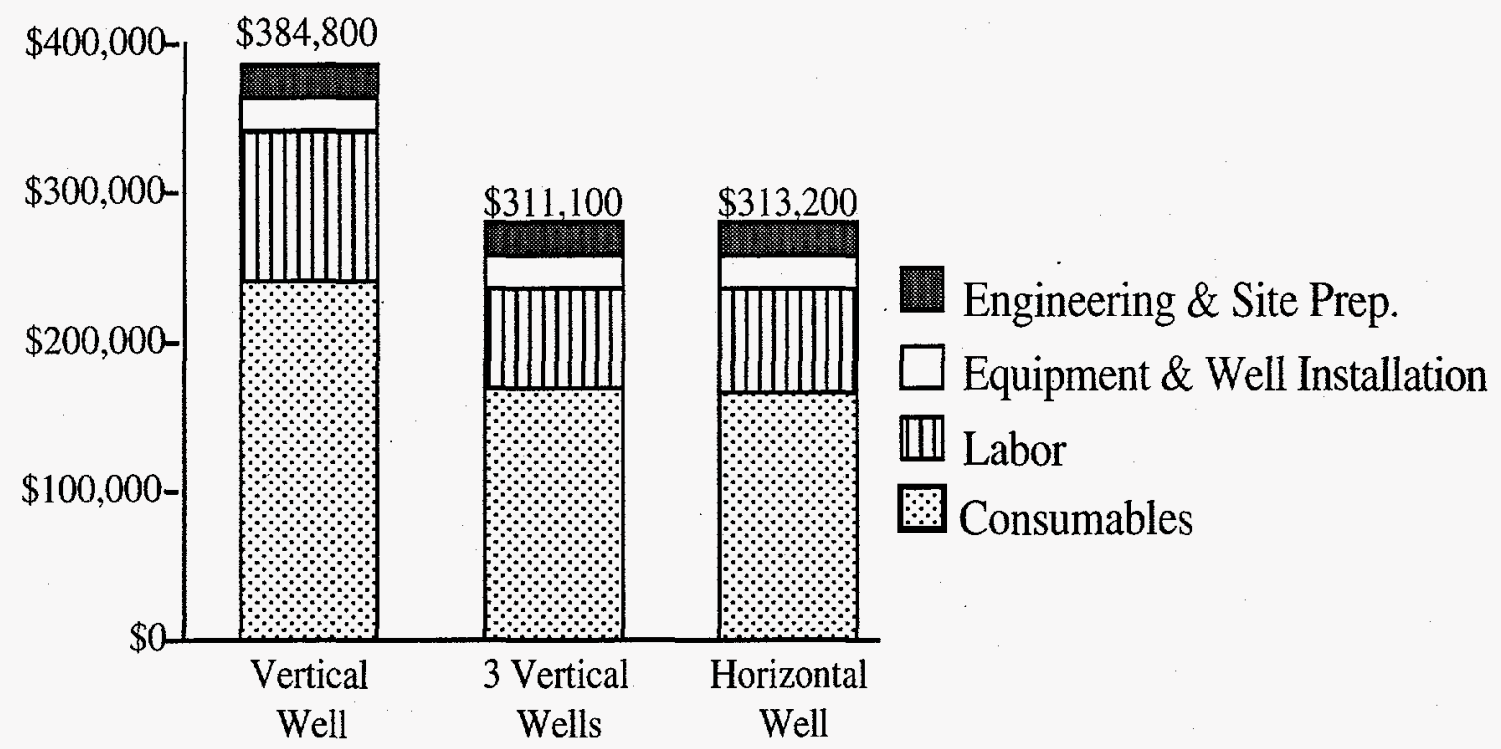

geology. For comparison of the cost effectiveness of horizontal vs. vertical vapor extraction wells we consider a TCE contaminant plume 240 $\mathrm{ft} \times 120 \mathrm{ft} \times 30 \mathrm{ft}$, with the center of the plume located $30 \mathrm{ft}$ bgs in a compactible geology. Vertical wells are installed using hollow stem augering, approximately $\$ 50 / \mathrm{ft}$ cased and screened, and the horizontal well is installed using Ditch Witch equipment, approximately $\$ 68 / \mathrm{ft}$ cased and screened.

The bar diagram compares the cost of installing and operating a single vertical vapor extraction well $45 \mathrm{ft}$ bgs and screened over the lower $15 \mathrm{ft}$, $(\$ 384,800)$ to the cost of installing and operating a single horizontal vapor extraction well with a $240 \mathrm{ft}$ horizontal screened length at $30 \mathrm{ft}$ bgs $(\$ 313,200)$. This diagram also shows the installation and operating cost for three vertical SVE wells within the plume $(\$ 311,100)$. Here the increased performance of both the horizontal

well and the three vertical wells is assumed to provide a $30 \%$ reduction in the required operating time. The single horizontal well shows a cost savings of roughly $\$ 70,000$ over the single vertical well. If the performance of three vertical wells is assumed to be equivalent to the performance of the single horizontal well, however, the costs of these two alternatives are nearly equal. If this assumption is accurate, the most important consideration in choosing horizontal vs. vertical wells may be simple practicality. This includes issues such as access, plume location and zone location. If three or four vertical wells are to be used, the site being remediated will be unusable for the duration of remediation activities. However, use of a single horizontal well may allow the area above the contamination to be used during remediation activities. In addition, a single horizontal well may be far more aesthetically pleasing and publicly acceptable than three or four manifolded vertical wells. 


\section{Ongoing Developments}

Improvements in the Ditch Witch technology are ongoing at this time with current emphasis on identifying better and stronger casing and screening materials. CMW and SNL are continuing in their efforts to educate regulators and potential users in the environmental industry about the new technology and potential applications. It may be necessary to approach regulatory agencies to modify current drilling regulations to accept horizontal boring as a viable technology. The relative cost per foot of this method should not be expected to decrease significantly as a result of future developments and can be expected to continue to range from $\$ 50$ $\$ 75$ per foot.

\section{Conclusions}

- The Ditch Witch technology was designed to install shallow (less than $80 \mathrm{ft}$ ) horizon tal boreholes and wells in compactible geologies. When used in applicable situations, it can provide significant cost savings.

- The most significant advantages of Ditch Witch are its low cost when compared to other horizonțal drilling methods and its ability to install wells and boreholes with little or no secondary waste generation.

- Costs for the Ditch Witch methods normally range between $\$ 50-\$ 75$ per foot for installation of a horizontal well. This is significantly less than most other horizontal drilling methods. Other methods with costs in this range are typically waste intensive.

- Consideration should be given to the acceptability of a compacted borehole wall resulting from use of Ditch Witch technology and no additional perforation of the wall.

\section{References}

[1] Birdsell, K.H., Rosenberg, N.D., Edlund, K.M., "Performance of Horizontal Ver s u s Vertical Vapor Extraction Wells", June 1994, LA-12783-MS.

[2] Schroeder, J.D., Rosenberg, N.D., Barnes-Smith, E.P., Booth, S.R., "In Situ Air Stripping: Cost Effectiveness of a Remediation Technology Field Tested at the Savannah River Integrated Demonstration Site", June 1992, LAUR-92-1927.

[3] Wemple, R.P., Meyer, R.D., Layne, R.R., "Interim Report for SNL/NM Environmental Drilling Project", March 1994, SAND93-3884 UC 402.

[4] Wemple, R.P. facsimile, 6/27/94. 


\section{The Direct Sampling Ion Trap Mass Spectrometer}

- The Direct Sampling Ion Trap Mass Spectrometer (DSITMS) can be used to analyze water, air, soil, sediment, and some solid samples for the presence of a large number of volatile organic compounds (VOCs)

- DSITMS can be used to analyze all 34 VOCs on the EPA's target compound list

- DSITMS is unique because the introduction of the sample into the instrument does not require any preparation

- DSITMS can analyze samples in less than five minutes

- The cost per sample is about $20 \%$ of the amount charged by commercial labs using analytical methods currently approved by the EPA.

- DSITMS has a per sample cost of $\$ 46$ (5 year life cycle and 3500 analyses per year). A commercial lab has a typical per sample cost of $\$ 254$.

- The detection limits of the DSITMS are well within the range required by the EPA (parts per billion and even parts per trillion)

- Compared to other field screening technologies, the DSITMS has the highestpossible sample analysis capacity

- At maximum capacity, the cost per sample of the DSITMS decreases $25 \%$ to a low of $\$ 33$.

\section{Analysis and Caveats}

The cost and performance characteristics of the DSITMS, with respect to standard sample analysis methodology, are described under three two- phase scenarios: the first phase is a site characterization in which soil and groundwater samples over a given geographic area must be analyzed so that the geographic dimensions and depth of a leachate plume can be mapped out; the second phase is a remediation situation in which the soil and the groundwater must be sampled regularly and frequently to determine the change in contaminant levels as the remediation process proceeds. The three different scenarios offer a cost per sample comparison as follows: the DSITMS only, the DSITMS with $20 \%$ of the samples sent concurrently to a commercial analytical laboratory, and commercial analytical laboratory analysis only. The DSITMS is also compared to five other field screening technologies in terms of cost per sample and performance capabilities. The combination of rapid results, cost effectiveness, convenience, accuracy, precision, and sensitivity makes the DSITMS a valuable analytical tool for environmental applications. The critical caveat to the presented results is that field screening data (or some combination of field screening and use of commercial laboratory analysis) must be accepted as valid by the EPA. If the EPA does not accept field screening results as valid, then field screening does not replace anything; it becomes an added cost.

\section{Perspectives and Calculations}

A measurement of the cost effectiveness of the Direct Sampling Ion Trap Mass Spectrometer was found in a comparison of the cost per analysis for the DSITMS and for a commercial labo 
ratory. Through the examination of three scenarios, it was determined that DSITMS is clearly a preferable alternative to sending $100 \%$ of the samples to a commercial laboratory. To obtain a cost per sample for commercial laboratory analysis, data from five commercial laboratories for standard RCRA-specific VOC methods was used; the additional charges associated with CLP reporting protocols were not included. The total annual revenues of the five commercial laboratories ranged from $\$ 12 \mathrm{M}$ to $\$ 70 \mathrm{M}$. The standard price for VOC analysis of water samples went from a low of $\$ 150$ to a high of $\$ 334$ with a mean of $\$ 249$ and a standard deviation of $\$ 68$. For purposes of the cost comparison, we chose to use a cost per sample analysis by the commercial laboratory of $\$ 250$.
The total cost per sample is calculated by dividing the present value of the total capital plus lifecycle operating costs by the total number of samples to be analyzed over the life cycle. For the DSITMS, the total cost per sample is about $\$ 46$; for the conventional analytical methodology, the total cost per sample is about $\$ 254$. This amounts to a cost savings ratio of over 5 to 1 ; that is, for what it costs to analyze one sample using the conventional technology, the new technology can produce results on over 5 samples. Another way to look at the cost savings is that one sample analysis using the DSITMS costs about $20 \%$ of that using the conventional methodology, in this case, a commercial laboratory.

In order not to bias the results in favor of the

\section{COST PER ANALYSIS* \\ For Commercial Lab vs. DSITMS Field Screening}

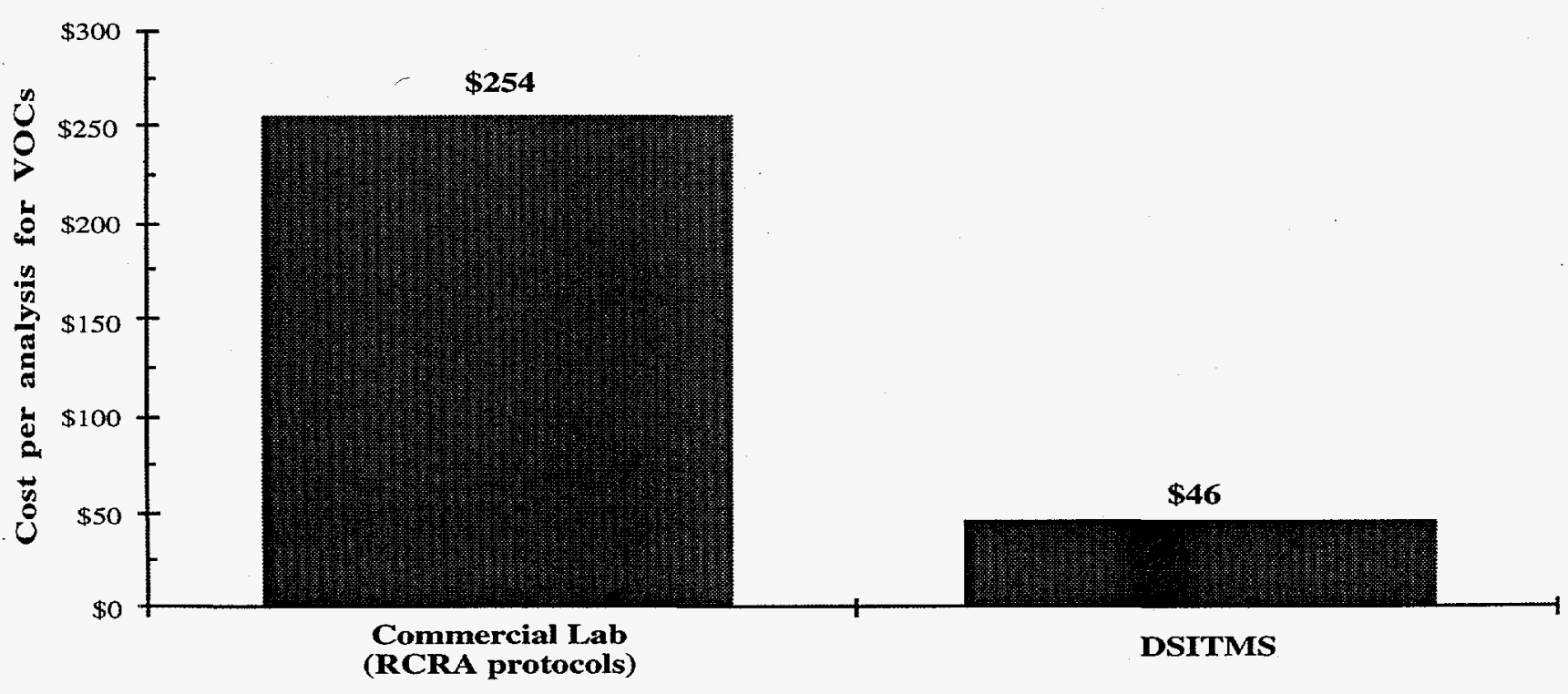

* 3500 analyses per year over 5 year life cycle 
new technology, any judgments involving costs were always made in favor of the conventional methodology. For example, a commercial laboratory cost per sample range of $\$ 200-\$ 400$ was provided to us, but $\$ 250$ per sample analysis at the lower end of that range was used in the total cost per sample calculation instead of selecting the highest value.

Another possibility is the scenario in which all of the analyses were done by the DSITMS, but $20 \%$ of the samples were sent as splits to a commercial laboratory. The cost savings are calculated by adding the commercial laboratory cost per sample for the percentage sent to the commercial laboratory to the total costs of the DSITMS and subtracting that figure from the total costs of sending all of the 3500 samples to the commercial laboratory.

The total cost savings attainable from using only the DSITMS instead of an off-site lab to analyze 3500 VOC samples is almost $\$ 800,000$ in the first year of operation. The concurrent use of both the DSITMS and a commercial laboratory, sending splits of $20 \%$ of the 3500 samples to the commercial laboratory, would save over $\$ 600,000$. Employing field screening methods concurrent with some percentage validation by a commercial laboratory would be the most likely scenario in which to best utilize such field deployable technologies.

A comparison is also done of the cost and performance characteristics of the DSITMS to five other field screening (FS) technologies. The five
FS technologies include a field transportable gas chromatograph/mass spectrometer system developed at Los Alamos National Laboratory (LANL), a field transportable GC/MS system marketed by Hewlett-Packard (HP 5890), a field transportable GC/MS system marketed by Viking Instruments (Viking), a truly portable GC marketed by Photovac (PVac) and a portable GC marketed by Sentex. The principle cost difference between the various FS technologies depended on their individual versatility. The cost of acquiring and implementing any of these technologies varied from $\$ 41$ to $\$ 51$ dollars per sample using an annual sample analysis rate of 3500. An average life-cycle present value cost per sample is calculated for each technology at a $4 \%$ discount rate. This is done by dividing the present value by the total number of sample analyses to be performed over the time period (3500 per year for five years).

The DSITMS has a cost per analysis of $\$ 46$. The GS/MS system developed at LANL has a cost per analysis of $\$ 48$. The HP 5890 developed by Hewlett Packard costs $\$ 45$ per analysis. The field screening technology developed by Viking Instruments has a cost of $\$ 51$ per analysis. The GC marketed by Photovac is about the size of a suitcase, can be easily transported, and has a cost of $\$ 41$ per sample analysis. Another portable GC, marketed by Sentex, has a cost of $\$ 42$ per analysis. All the figures assume the same number of analyses (3500) over the five year life cycle.

At maximum capacity levels, where sample availability is not limited and the field screen- 


\section{COST PER ANALYSIS* \\ For Selected Field Screening Technologies}

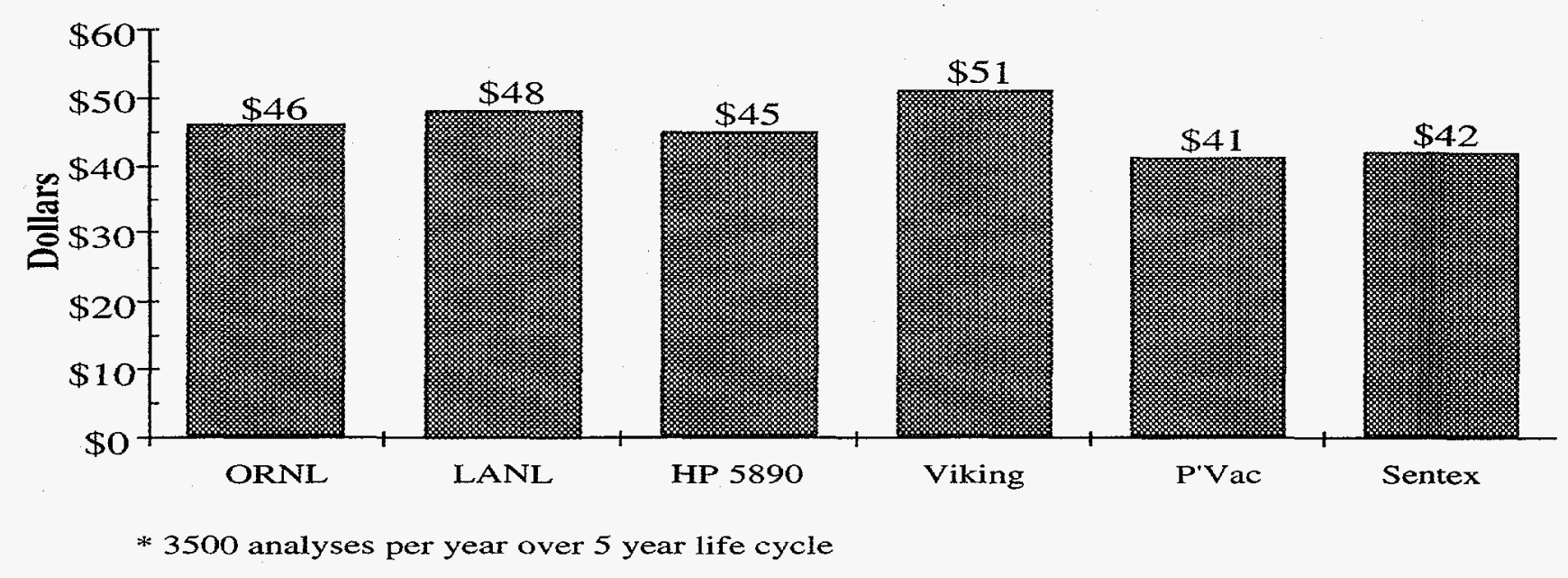

ing instrument can perform at theoretical peak productive levels, the DSITMS has the highest possible sample analysis capacity because of its quick turnaround time. The DSITMS can analyze a sample in approximately 3 to 5 minutes. This turnaround time decreases the cost per sample. At maximum capacity, the cost per sample for each of the technologies ranges from a low of $\$ 33$ to a high of about $\$ 41$. For the DSITMS, the cost per sample analysis goes from about $\$ 46$ to about $\$ 33$, a net decrease of $25 \%$. This represents a distinct advantage for the DSITMS in situations where a high sample analysis rate and rapid turnaround time are necessary.

\section{Applicability}

The DSITMS is capable of measuring volatile organic compounds at the parts per billion (ppb) level in a variety of sample media including air, water, soil, sediments, and solids. The DSITMS does not handle multi-component mixtures at greater than about 5 very well due to a lack of GC separation and to current software limitations. Therefore the DSITMS is most applicable to those sites where the contaminants are few and well defined. The DSITMS is modified with a rugged base and can be mounted in a van or 4wheel drive vehicle and used with a $\mathrm{Pb}$-acid battery, so it is extremely portable and could be moved from site to site. The DSITMS also facilitates real-time mapping of the contaminant plume and correct monitoring-well placement.

\section{Conclusions}

- The added use of DSITMS is clearly a preferable alternative to sending $100 \%$ of the samples to a commercial laboratory

- Using DSITMS with $20 \%$ of the samples sent concurrently to a commercial lab could save $\$ 600,000$ per 3500 samples 
- The principal advantages of the DSITMS are its speed, simplicity, convenience, and sensitivity

- DSITMS represents a cost savings ratio of 5 to 1 compared to commercial laboratories

- Compared to other field screening technologies, the DSITMS costs $\$ 33$ per sample at maximum capacity

- Field screening could save the Department of Energy about \$208 per sample analysis compared to using a commercial laboratory

\section{References}

Henriksen, A.D. and Booth, S.R. "Cost Effectiveness of an Innovative Technology for VOC Detection: The Direct Sampling Ion Trap Mass Spectrometer." Los Alamos National Laboratory report submitted to the U.S. Department of Energy, October 1992.

Henriksen, A.D. and Grant, D.E. "Cost-Effectiveness of Field Screening for VOCs," in Proceedings of the ACS Industrial \& Engineering Chemistry Division Fifth Annual Symposium on Emerging Technologies in Hazardous Waste Management, Atlanta, Georgia, September 2729, 1993, Los Alamos National Laboratory report LA-UR-93-2405 (September 1993), submitted for publication. 


\section{In Situ Vitrification}

- In situ vitrification (ISV) is a thermal treatment technology for the destruction of hazardous waste in soils

- In situ vitrification is applicable to hazardous inorganic and organic, radioactive, and mixed wastes

- ISV results in a durable end product, permanent destruction of the organic components, and reduced handling and exposure to contaminated soil

- ISV can process from 800 to 1000 tons of contaminated soil in a single setting, at a rate of about 4 to 6 tons per hour

- The final waste form generated by ISV is capable of passing the EPA's EP-Tox, SWLP, and TCLP leach tests

- At 5\% moisture, ISV costs $\$ 580$ per cubic meter, versus $\$ 2062$ per cubic meter for incineration

- ISV eliminates secondary waste handling which can result in savings of $70 \%$

\section{Analysis and Caveats}

In situ vitrification (ISV) is a promising thermal treatment technology for either the destruction or the immobilization of hazardous materials in contaminated soils. ISV melts undisturbed soil into an obsidian-like glass and crystalline waste form by applying electric current $(3750$ $\mathrm{kW}$ ) between symmetrically spaced electrodes. Temperatures of $1600^{\circ}$ and $2000^{\circ} \mathrm{C}$ destroy com- plex organics or drive them off to be captured in an off-gas treatment system, while radio-nuclides are incorporated into the glass monolith.

A comparative life-cycle cost evaluation between transportable rotary kiln incineration and ISV was performed to quantify the differences in cost between these two technologies. Predictions of melt times and power consumption were obtained from an ISV performance model over ranges of several parameters including electrode spacing, soil moisture, melt depth, electrical resistivity, and soil density. These data were coupled with labor requirements, capitalization costs, and a melt placement optimization routine to allow cost estimation over a wide variety of site characteristics.

One of the difficulties in comparing new technologies to established technologies is handling research and development costs as well as other costs associated with bringing a new technology to the field. Each technology is treated as though it was already established and only requires the appropriate engineering to bring them to a specific site. Charging only the new technology with $R \& D$ costs would be unfair, so this component is left out of the analysis.

\section{Cost Drivers}

The following pie charts, one for ISV and one for incineration, show a few of the major cost 
drivers at a cost per ton amount. On the incineration chart, secondary waste, at a cost of $\$ 974$ per ton, takes up a major portion of the pie, about two-thirds. On the ISV chart, secondary waste, at a cost of $\$ 0.001$ per ton, is so minor that it cannot be seen as a separate item and appears as the boundary between operations and other. The cost of secondary disposal is the most expensive component of the cost of incineration. ISV creates a vitrified mass that may be left in place, while incineration requires that the residual be moved to monitored storage.

ISV process equipment specifications have been taken from an actual bid by the vendor for remediation of a U.S. Army site. The costs for equipment have been verified independently, and wage rates were adjusted to reflect national averages. The bid was based on the owner providing electric power, while our estimate in- cludes the costs for electricity based on a national average. All costs are actual costs and have been adjusted to June 1993 .

\section{Contingency}

Contingency is included in both cost estimates as a $15 \%$ addition. The contingency is included to more accurately reflect the total that a contractor might bid. Due to uncertainties about contaminated sites, such as the extent and nature of the contamination, and the regulations that may be applied, a contractor would likely include a mark up to cover unexpected costs. If the contract were on a cost plus basis, the contractors exposure to risk is low, and the contingency could also be lower. If the site is poorly characterized and the contractor is taking a lot of responsibility, the contingency could be

\section{Cost Drivers of ISV versus Incineration}

\section{Incineration}

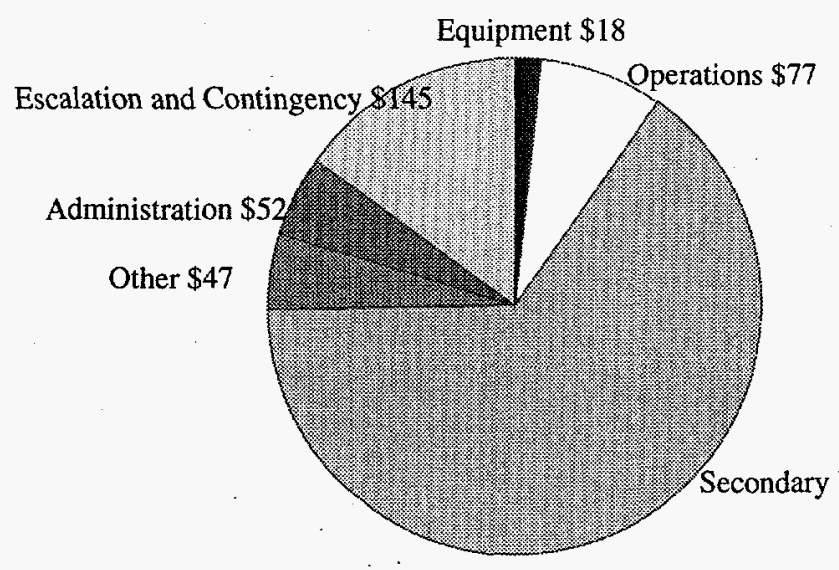

ISV

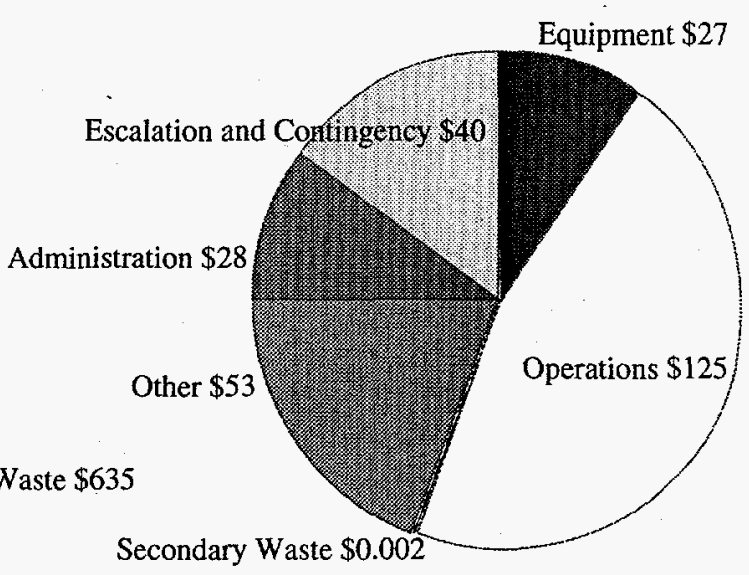


higher. For this reason, the contingency is calculated as a separate line item, and can be deleted if desired.

\section{Perspectives and Calculations}

The site where the two technologies will be applied is critical to the analysis. Changes in the type of waste or other factors will affect the cost of both processes. The site in this study is 30 meters wide by 90 meters long by 5 meters deep (13,500 cubic meters). The size of the site is slightly larger than the expected contaminated volume to account for small uncertainties in the exact location of the perimeter. The soil is homogeneous and contaminated with low-level radioactive mixed waste. Costs have been esti- mated at soil moisture content of $5 \%, 10 \%$, and $15 \%$. The entire contaminated site is located within a larger government-owned facility. Based on the scenario that was developed, ISV is significantly less expensive than incineration. At 5\% moisture, ISV was found to cost $\$ 580$ per cubic meter, versus $\$ 2062$ per cubic meter for incineration.

\section{Sensitivity Analyses}

Total costs estimates for ISV and incineration are influenced by certain unit costs. If these influential unit costs are also subject to uncertainty, then they could cause large fluctuations in the total cost. One unit cost that can affect the total

\section{Cost Comparison of ISV and Incineration*}

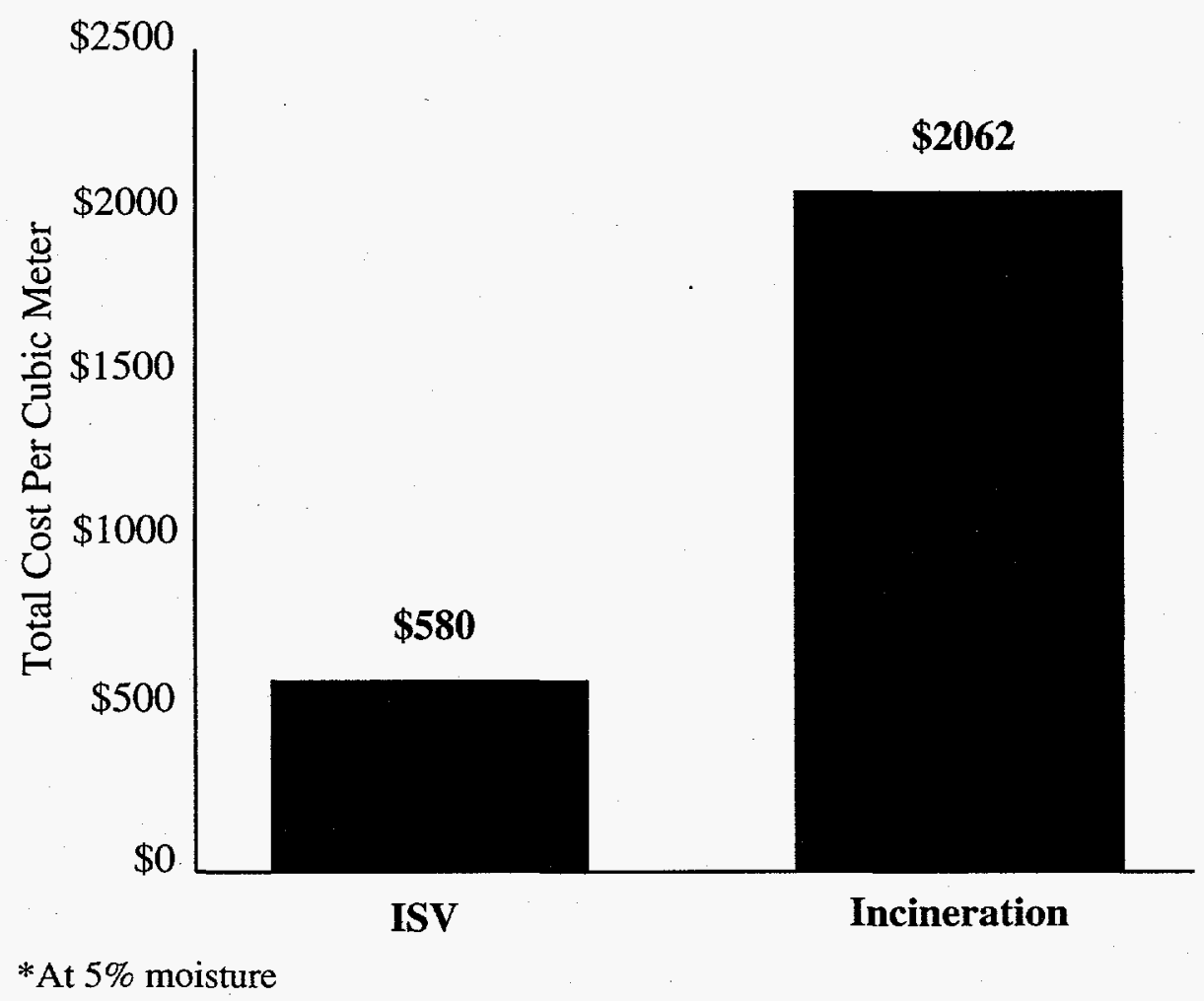


cost is long-term monitored storage. Especially in the case of incineration, storage is an expensive component. An analysis was made of both ISV and incineration, varying storage costs from $\$ 25$ to $\$ 150$ per barrel while holding all other costs constant. Storage costs do not influence ISV heavily, but incineration can fluctuate significantly with changes in secondary waste disposal cost. For incineration, storage costs can cause the total cost to vary from $\$ 24$ million to $\$ 33$ million. It is not likely that there will ever be a way to leave the incinerator residual product on the site.

Transportation of secondary waste is also a significant cost, and one that will vary depending on the location of the site being cleaned relative to the location of the long term disposal site. The cost of ISV is not affected at all by cost of transportation since the residual product is left on site. Incineration cost is dependent on the cost of transportation, and hence the location of the remediation site relative to the disposal site is a factor to consider when selecting a technology.

Another factor to consider is the water content of the site that is being remediated. Five percent soil moisture content corresponds to very dry climate conditions. Costs are also calculated at $10 \%$ and $15 \%$ soil moisture. The total costs are summarized below:

With either technology, water in the soil can make a significant cost difference. Incinerator operation is especially sensitive to changes in soil moisture.

\section{Ongoing Developments}

As more experience with actual projects is gained, some costs of ISV can be expected to go down. The operation will become more efficient, and contingencies associated with this new technology will be reduced.

\section{Conclusions}

- Application of ISV to remediation sites can result in significant savings

- At $5 \%$ moisture, ISV costs $\$ 580$ per cubic meter, versus $\$ 2062$ per cubic meter for incineration

- ISV eliminates secondary waste handling which can result in savings of $70 \%$

\section{References}

W.E. Showalter, B.C. Letellier, E.P. BarnesSmith, and S.R. Booth, "Cost Effectiveness of In Situ Vitrification," Los Alamos National Laboratory report No. LA-UR-92-2071 (June 1992). 


\section{Site Characterization and Analysis Penetrometer System}

- The Site Characterization and Analysis Penetrometer System (SCAPS) is an effective tool for use in characterization and assessment of contaminated waste sites

- SCAPS data can be used to effectively guide other drilling, sampling, and monitoring efforts

- A major strength of SCAPS is its ability to utilize in situ chemical sensors for contaminant detection

- SCAPS can acquire a significant amount of data (42 to 92 cone penetrometer pushes) for the same cost as four conventional monitoring wells

- The largest factor in the cost effectiveness of SCAPS is its ability to avoid the installation of some very costly misplaced monitoring wells

- Cost savings of $30 \%$ to $50 \%$ over the use of conventional monitoring wells alone are possible assuming $50 \%$ of conventional wells can be avoided by the use of SCAPS

\section{Analysis and Caveats}

The Site Characterization and Analysis Penetrometer System (SCAPS) is an innovative environmental technology for characterizing soil types and detecting subsurface contaminants. It is a project of the U.S. Army corps of Engineers Waterways Experiment Station and has been tested as part of the Savannah River Integrated Demonstration. SCAPS is intended as a field screening technique to complement conventional drilling: information about soils and contaminants acquired by SCAPS can be used to determine better locations for fewer number of monitoring wells.

SCAPS is intended for use in clayey or sandy soil. It is also effective in small gravel and weakly cemented sandstone; it will not penetrate contiguous rock. SCAPS was never intended to supplant drilling, but rather to complement drilled wells. If it is tried in harsh geologic settings higher rates of failure (e.g., broken push rods) can be expected, and so it much be used judiciously. SCAPS is also applicable in the detection of specific contaminants. For instance, a sensor is available for semi-quantitatively detecting POL contaminants and a TCE sensor is under development. Other sensor development is being sponsored by DOE. The SCAPS system has been successfully field tested at at least 17 sites, predominantly in the southeastern United States.

\section{Cost Drivers}

The total cost for a SCAPS system is $\$ 809,200$. Amortized at a real rate of $5 \%$ over 5 years, the annual cost is $\$ 183,240$ per year. One of the significant cost drivers for the SCAPS system is the cost of labor; the labor cost is equivalent to $14 \%$ of the total cost. For the conventional technology, monitoring wells, a significant cost 
is the mandated ongoing monitoring. Conventional drilling leaves many non-useful wells which must be monitored or abandoned. The cost of monitoring these wells ranges from $10 \%$ to $30 \%$ of the total cost for each scenario. The costs for the monitoring wells are based on actual field experiences at the Savannah River Site. It is important to note that these cost comparisons are based on actual cost data; therefore, ranges of uncertainties were not considered in this cost-effectiveness analysis because actual cost data were available.

\section{Perspectives and Calculations}

The largest factor in the cost effectiveness of the SCAPS cone penetrometer system is its ability to avoid the installation of some very costly misplaced monitoring wells. In order to analyze the cost effectiveness of SCAPS as a complement to the conventional drilling methods, five scenarios were constructed. For each scenario, two possible plans were considered:

Plan 1: Site characterization by using the baseline technology only (i.e., monitoring wells)

Plan 2: Site characterization by using some combination of the baseline technology (i.e., monitoring wells) and the SCAPS cone penetrometer system.

Each of the five scenarios is based on a realistic geologic and/or waste site setting. The scenarios cover a range of scales (size of site), drilling methods, depths, and percentages of conventional monitoring wells that can be replaced by the use of SCAPS.

Scenario 1 is constructed to represent a site somewhat like the Savannah River Site. The drilling method is mud rotary, depths are 75 feet, and the target contaminant is TCE. In this scenario, 20 wells are required for conventional site characterization for Plan 1; and for Plan 2, 40 cone penetrometer locations and only 10 monitoring wells are used. For this case, the total cost for Plan 1 is $\$ 277,893$. Assuming that $50 \%$ of the conventional wells can be avoided with SCAPS, the total cost for Plan 2 is $\$ 142,833$. The use of SCAPS in Plan 2 represents a $49 \%$ savings in cost over Plan 1 for the given activities. The breakeven point occurs at about $15 \%$ of conventional wells avoided. This means that if Plan 2 can avoid as few as $15 \%$ of conventional wells, then the plan has saved money. Use of SCAPS demonstrates that significant cost savings are achievable in the range of reasonably expected situations (i.e., anywhere from $25 \%$ to $65 \%$ of conventional wells avoided).

In Scenario 2 a different drilling technology (hollow stem auger) and a shallow depth (50 feet) are considered. Due to differences in drilling cost and depth of the holes, the costs for well installation are now $\$ 7,687$ (no core) and $\$ 10,087$ (with continuous core). The breakeven point for costs is at slightly less than $10 \%$ conventional wells avoided by the use of SCAPS. At $50 \%$ of conventional wells avoid, the savings are $55 \%$. The higher cost of the shallow augering causes a slightly higher utility for use of SCAPS. Because a drilling rig requires more 
time to set up operations than the SCAPS system (which simply requires driving the truck to a new location), the economics of shallow investigations quickly favor the SCAPS cone penetrometer.

Scenario 3 considers a different kind of situation: an initial look at a new site. When no information is known about a site, a common practice is to install four monitoring wells. This scenario considers the possibility that instead of installing four monitoring wells for a cursory investigation, SCAPS pushes could be done. The cost of four monitoring wells (all augered with continuous cores to a depth of 100 feet, a 1 year time span, and a $5 \%$ discount rate) has a net present value life cycle cost of $\$ 72,944$. For a cost of $\$ 72,000$, a total of sixty total SCAPS pushes can be done (each to 100 feet depth). Sixty cone penetrometer locations would provide more data. Given an appropriate sensor, a 3-D, semi-quantitative map of contaminants can be generated. Anywhere from 42 to 92 cone penetrometer pushes can be done for the cost of installing and utilizing four monitoring wells, depending on the depth and drilling method (see figure).

Scenario 4 considers a very large site. This is done to investigate how the costs savings achieved by the use of SCAPS are affected by scale. The number of conventional wells is assumed to be 100 . The number of cone penetrometer locations used is 200 . Mud rotary drilling is used; all depths are 150 feet. The cost breakeven point occurs at $25 \%$ of conventional

\section{Number of SCAPS Pushes Equivalent in Cost to Four Monitoring Wells}

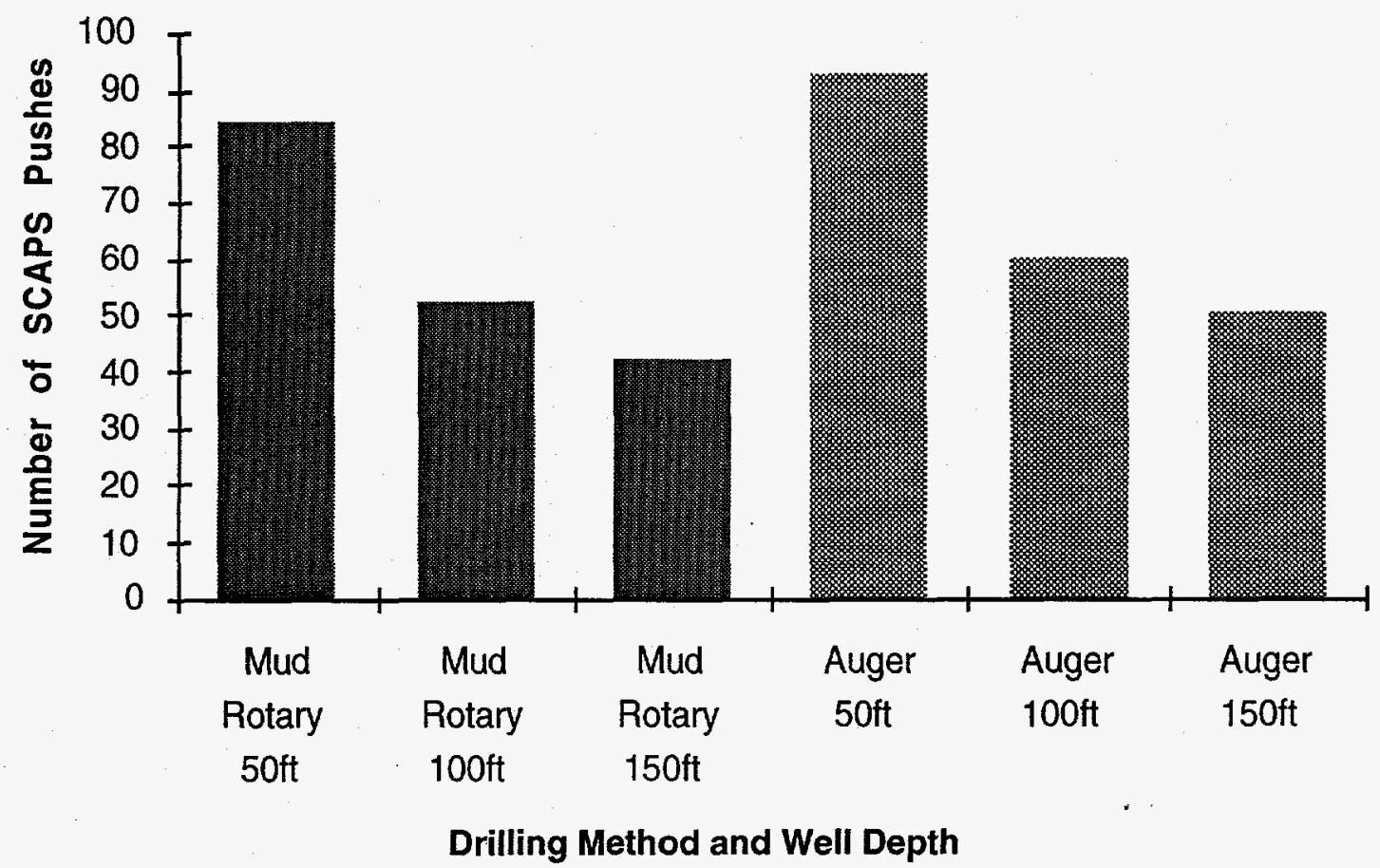


wells avoided by use of SCAPS.

In Scenario 5, job factors related to worker safety are applied to the cost of drilling a well and performing a cone penetrometer push. Scenario 5 is the same as Scenario 1 except for those additional costs for worker protection due to a radioactive environment; we also include higher analytical costs attributable to the presence of radioactive contaminants. Scenario 5 is not meant to be a comprehensive cost estimation. The percent savings between Plan 1 (wells only) and Plan 2 (SCAPS plus wells) are higher for the radioactive site than the nonradioactive site studied in Scenario 1. In Scenario 5 there is a lower breakeven point in costs, meaning that even fewer conventional monitoring wells may be avoided in order for the use of SCAPS to be cost effective. Therefore, there is an even higher cost savings achievable by the use of SCAPS at a radioactive site. It must be emphasized that this scenario is speculative and does not consider all aspects of working at a radioactive site. SCAPS has not been used in a radioactive environment to date, so this section merely illustrates some possible trends and considerations.

\section{Ongoing Developments}

There are several areas that have been identified for ongoing development in the SCAPS system. These areas will serve to increase the utility of SCAPS. The performance and economic assessments of SCAPS can be expected to change in the future as the new technology evolves or does not evolve, relative to the accepted baseline technology. The areas that have been identified for ongoing development in- clude:

- Sensor Development: Sensors that are of sufficient specificity and sensitivity must be developed. Developments will be required for contact sensors, and also for monitoring sensors that are intended for permanent emplacement.

- Automation: Robotics could be used to automated the compartment of the truck where push rods are assembled and disassembled as the penetrometer rod is inserted into the ground and then withdrawn. In this manner, worker exposure to contaminated push rods (especially important in a radioactively contaminated area) can be avoided. Worker exposure to contaminants would be avoided and significant savings could be obtained in worker protection costs.

- Improved Mapping Capability: Global positioning systems can be utilized for precisely mapping the locations of cone penetrometer pushes

- Enhanced Data Analysis: The addition of a portable gas chromatograph/mass spectrometer (GC/MS) in the field can provide for immediate data analysis of physical samples. A library of spectral responses can be maintained in the field. A Silicon Graphics workstation can be added to the field equipment for rapid 3-D data visualization. 


\section{Conclusions}

- Scenarios 1 through 4 demonstrate that significant cost savings are possible with the use of SCAPS

- Cost savings of $30 \%$ to $50 \%$ are possible with the use of SCAPS

- SCAPS can avoid the cost of installation, monitoring, and abandonment of non-useful wells

- SCAPS can obtain significant data for the same cost as four monitoring wells

- SCAPS can achieve a better site characterization for the same cost as the conventional technology. A better site characterization can lead to a more efficient, and thus less costly, site remediation

- Rapid ongoing development indicates that SCAPS will be an even more powerful site characterization tool in the future

\section{References}

Schroeder, J.D., Booth S.R. and Trocki, L.K. "Cost Effectiveness of the Site Characterization and Analysis Penetrometer System." Los Alamos National Laboratory report LA-UR-914016, submitted to Department of Energy, December 1991 


\section{In Situ Bioremediation}

The purpose of this report is to study the cost effectiveness of In Situ Bioremediation (ISBR) with horizontal wells as tested at the Savannah River Integrated Demonstration (SRID) site in Aiken, South Carolina. ISBR is an innovative new remediation technology for the removal of chlorinated solvents from contaminated soils and groundwater. The principal contaminant at the SRID is the volatile organic compound (VOC), trichloroethylene (TCE). A 384 day test run at Savannah River, sponsored by the U.S. Department of Energy, Office of Technology Development (EM-50), furnished information about the performance and applications of ISBR.

- The overall cost effectiveness of In Situ Bioremediation (ISBR) is based on the cost sensitivity of the biological component; as the biological addition increases, the cost per pound of VOCs remediated decreases.

- The short-term cost of ISBR with a biological addition of $40 \%$ above the vacuum component is $\$ 21$ per pound of VOCs remediated. The worse case scenario, ISBR $+0 \%$ addition costs $\$ 29 / \mathrm{lb}$ of VOCs remediated, and is based solely on the vacuum component.

- The baseline pump and treat/soil vapor extraction system costs $\$ 31 /$ $\mathrm{lb}$ in the short-term and has no possibility of a biological addition.

- Life-cycle analysis shows that
ISBR is more cost effective than the baseline pump and treat/soil vapor extraction system.

- As demonstrated, ISBR has a possible savings of $\$ 1$ million at the SRID site alone.

In Situ Bioremediation is based on two distinct processes occurring simultaneously: the physical process of in situ air stripping and the biological process of bioremediation (see figure). Both processes have the potential to remediate some amount of contamination. A quantity of VOCs, directly measured from the extracted air stream, was removed from the test area by the physical process of air stripping. The biological process is difficult to examine. However, the results of several tests performed at the SRID and independent numerical modeling determined that the biological process remediated an additional $40 \%$ above the physical process. Given this data, the cost effectiveness of this new technology can be evaluated. In addition to calculating the cost effectiveness on the ISBR demonstration at the SRID, sensitivity analysis is conducted in order to determine how the overall cost of ISBR changes in regards to the performance of the biological component. By comparing the overall cost of this system and the price per pound of VOCs remediated against a conventional pump and treat/soil vapor extraction system, we can evaluate the overall cost effectiveness of the alternative technologies. 


\section{Schematic Diagram of the Two Processes Involved in In Situ Bioremediation}

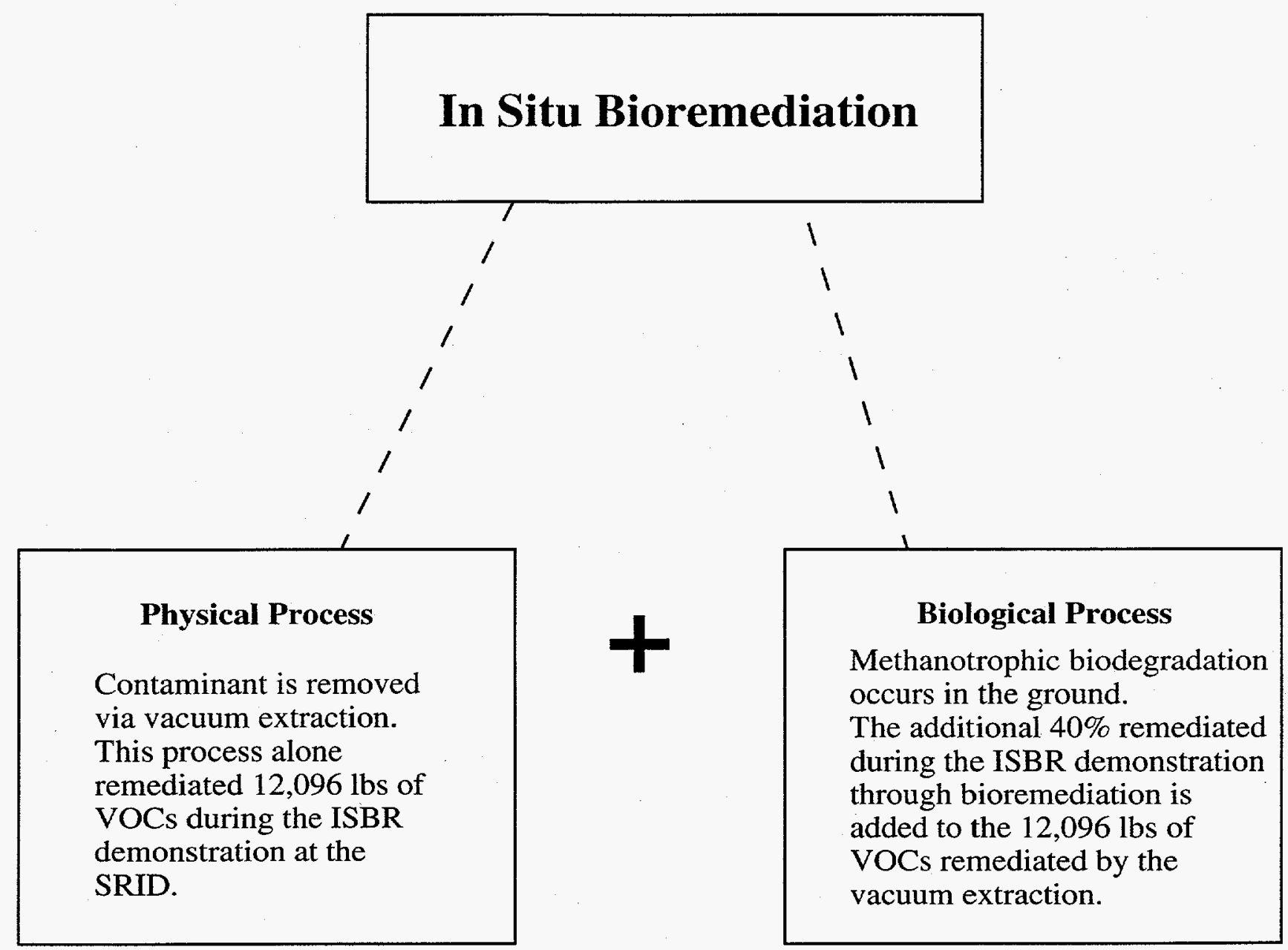

\section{System Caveats}

The In Situ Bioremediation field demonstration at the SRID site is fully described in Test Plan for In Situ Bioremediation Demonstration of the Savannah River Integrated Demonstration Project [Hazen 92]. The ISBR demonstration at the SRID was set up to address a "hot spot" of an overall larger VOC contaminant plume.

The pump and treat/soil vapor extraction sys- tem is engineer designed and presumed to perform optimally. Both pump and treat and soil vapor extraction systems have been tested at the SRID. The baseline system (a combination of pump and treat/soil vapor extraction apparatus) is integrated to avoid overlapping of equipment and materials, and is located in an area exactly like the ISBR demonstration in regards to all necessary site characteristics, including overall concentration of contaminants. By designing 
both the baseline and the innovative systems to handle equal flow and assuming equal vacuum extraction performance, a level playing field for a cost comparison is created.

\section{Analysis}

The data used in these analyses have a "field demonstration" level of confidence and are based on an actual field demonstration. The performance comparison consists of Plan 1, which is based on the new ISBR technology as demonstrated at the SRID, and Plan 2, which is based on "equivalent" conventional technologies, pump and treat/soil vapor extraction, necessary to remediate the contamination problems addressed by ISBR. Plan 2 is constructed so that it remediates the same conditions treated by ISBR at the SRID. In order to be fair to both technologies, equal physical process performance is forced from both Plan 1 and Plan 2. Plan 1 and Plan 2 are compared based on what it costs to operate them over equal periods of time. Performance data indicate that the vacuum component of ISBR destroyed 12,096 pounds of VOCs in 384 days, and an additional $40 \%$ above the vacuum component was destroyed by bioremediation. The vacuum component data is used in the pump and treat/soil vapor extraction system, assuming that the equal flow rates will remove the same quantity in an equal amount of time.

The ISBR system, as tested, uses two horizontal wells. The first well is an injection well, 300 $\mathrm{ft}$ long and $165 \mathrm{ft}$ deep (about $35 \mathrm{ft}$ below the water table). The second well is an extraction well, $175 \mathrm{ft}$ long and $75 \mathrm{ft}$ below the surface (in the vadose zone). A concentration of methane (between 1\% and 4\%) and any necessary chemical nutrients (nitrogen in the form of nitrous oxide and phosphorus in the form of triethyl phosphate) are blended into the injected air stream to create a biological element for remediation. The methane provides the necessary material substrate for the indigenous microorganism to produce the enzyme methane monooxygenase which, in turn, degrades the principal contaminant, trichloroethylene (TCE). For the conventional technologies used in Plan 2 , four vertical SVE extraction wells are assumed to be equal in area influenced to the one horizontal extraction well of ISBR. One vertical pump and treat well is also used. Volatilized contaminants from both remediation systems are sent to a catalytic oxidation off-gas system where they are destroyed.

Economic comparisons for short-term costs are made by relying on actual field data and using cost sensitivity analysis; life-cycle costs are estimated in relation to possible time to achieve cleanup. The first economic comparison is a calculation of the short-term costs in relation to performance. Short term costs are those expenses incurred during the immediate field test demonstration of the technologies compared (generally about a year). The equipment capital costs are amortized yearly over the useful life of the equipment, which is assumed to be 10 years. All short-term equipment costs are amortized at $7 \%$, which is the interest on the loan.

For ISBR there is a total cost of about $\$ 354,000$ 
with total 16,934 pounds of VOCs being destroyed by the vacuum component and biological component, giving a cost per pound of VOCs remediated at about $\$ 21$. The integrated pump and treat/soil vapor extraction with 4 vertical SVE wells has a total cost of about $\$ 380,000$. Assuming an equal vacuum extraction performance of 12,096 pounds of VOCs removed, the integrated system has a cost per pound of VOCs remediated at about $\$ 31$. A ratio of ISBR to the baseline shows that ISBR is $32 \%$ less expensive than the baseline.

Next, an analysis of life-cycle cost is conducted. A real discount rate of $2.3 \%$ is used to calculate the present value. ISBR, with its combination of vacuum component and bioremediation, costs $\$ 1$ million and remediates the site in only 3 years. The baseline takes 10 years to remediate the site and costs $\$ 2$ million. ISBR, therefore, saves $\$ 1$ million and 7 years of remediation. Even when we assume the baseline can perform at twice the expected time and cleans the site in only 5 years, it still costs $\$ 1.4$ million. ISBR still beats the baseline by $\$ 400,000$ and 2 years remediation time.

Where ISBR has the potential to exceed the baseline technologies is its ability to remediate a portion of the contamination in situ, thereby

\section{Comparison of Short Term Costs with Various Biological Additions}

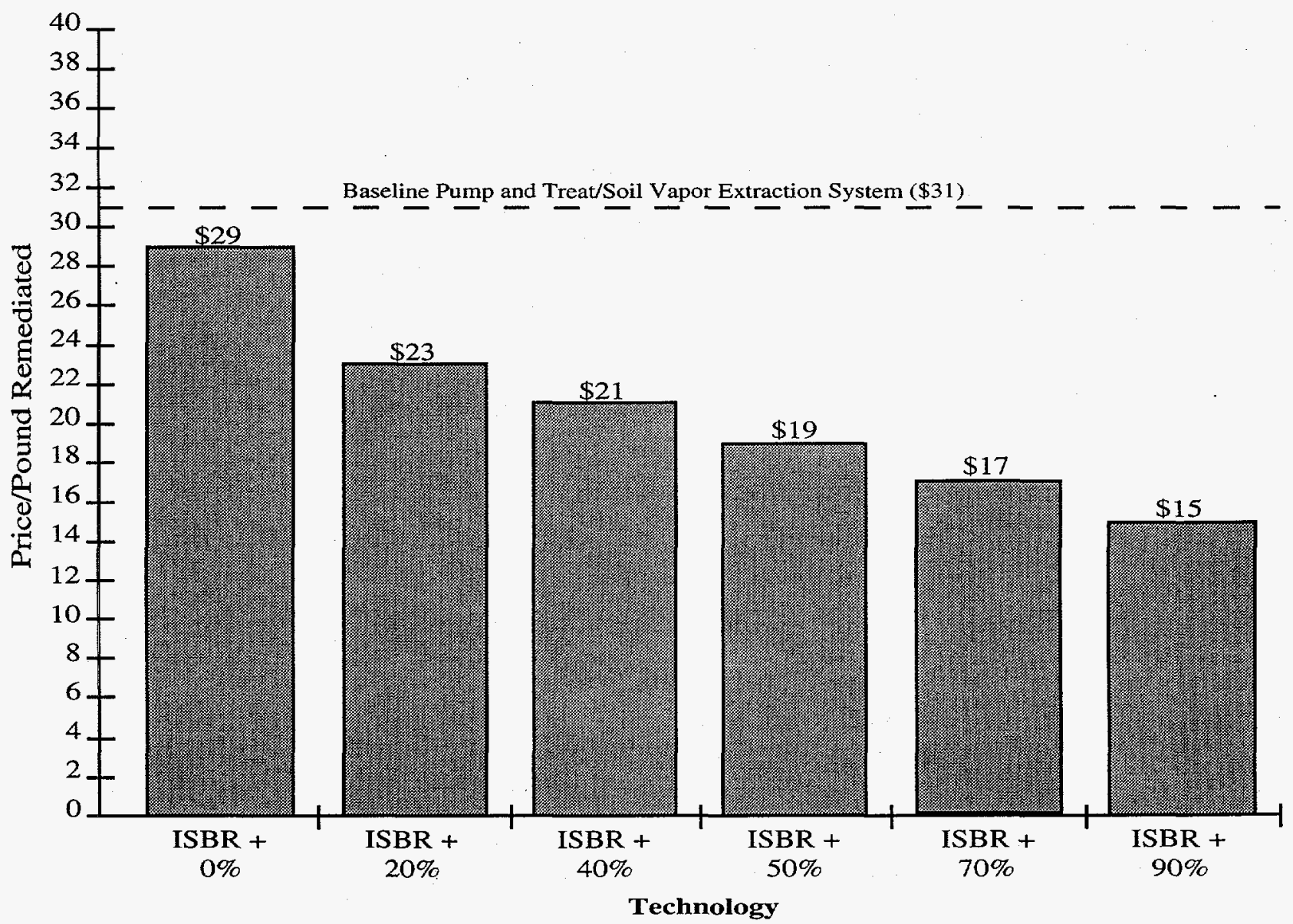


eliminating the need to physically remove the contaminant and process it. Since ISBR relies heavily on the biological component to achieve greater performance, sensitivity analysis is conducted to compare the cost per pound of VOCs remediated versus the performance of the biological component. Of particular interest is ISBR $+0 \%$ addition. This is a worse case scenario based on a $0 \%$ addition from the biological component. It assumes that all the necessary materials are added to stimulate the biological addition, but no additional remediation occurs. In this situation, ISBR still costs slightly less than the baseline, $\$ 29$ versus $\$ 31$, respectively. By adding a percent addition of pounds of VOCs destroyed by bioremediation in addition to that removed via the vacuum component, we can examine how the cost per pound changes with respect to the biological component. Six hypothetical percentages are used to account for the bioremediation levels: $0 \%, 20 \%, 40 \%, 50 \%$, $70 \%$, and $90 \%$. The following figure shows the various hypothetical additions and the decrease in cost per pound of VOCs remediated.

The baseline technologies in Plan 2 have a constant price per pound of VOCs remediated of $\$ 31$ because there is no biological component. As the biological addition of ISBR increases, the price per pound of VOCs decreases. So, even in the worse case scenario where no bioremediation occurs, ISBR breaks even with the baseline. There is, therefore, no cost risk to run ISBR over the baseline system. The savings, however, are quite substantial when the biological component is stimulated. In order for the biological component to occur, it is necessary to inject methane and nutrients into the system. Without this material, only the physical, vacuum component of ISBR is possible. Because the cost of the biological component is so inexpensive, ISBR only has to remediate an additional 1,570 lbs of VOCs over the 12,096 lbs of VOCs remediated with the vacuum component in order for the system to completely pay for the cost of the methane injection. Any additional remediation is achieved at no extra cost and increases the cost savings of ISBR over the baseline technologies.

Next, the total present value cost for operating each plan for five years, including all necessary equipment, is computed. The total equipment costs are included in the first year so that no amortization is needed. As with the short-term cost, the potential cost-savings for ISBR lie with its ability to remediate VOCs in additon to the physical process, thereby lowering the cost per pound and increasing the total amount remediated over equal time. The same hypothetical percent additions of $0 \%, 20 \%, 40 \%$, $50 \%, 70 \%$, and $90 \%$ are used.

\section{Perspectives and Cost Drivers}

The two largest categories in regards to cost for both ISBR and the baseline system are the costs of consumables and labor. The labor and consumables are greater than $85 \%$ of the overall operating costs; therefore, if the overall remediation time of the project is shortened, the 
cost will drop. This is due to the nature of the labor and consumables which are incurred each day of operation. Since ISBR can significantly decrease operation time, ISBR lowers the overall cost of the remediation effort.

\section{Applicability}

ISBR can be very effective in settings where some interbedded thin and/or discontinuous clays are present. ISBR should prove even move successful than in situ air stripping alone because ISBR contains a biological component as well as the physical air stripping process. A potential concern with the use of ISBR is the possible lateral spread of the contaminant plume. If the geology constricts vertical flow, the injection process can push the dissolved contamination concentrically from the injection point. Thus, it may be advisable in heterogeneous formations to use ISBR in conjunction with a surrounding pump and treat system that provides hydraulic control at the site. Note that the limitations on applicable geologic settings described above also apply to soil vapor extraction and pump and treat systems.

\section{References}

Saaty, R. P., W.E. Showalter, and S.R. Booth, "In Situ Bioremediation: Cost Effectiveness of a Remediation Technology Field Tested at the Savannah River Integrated Demonstration Site," Los Alamos National Laboratory report No. LAUR-94-1714 (November 1994). 


\section{SEAMIST ${ }^{\mathrm{TM}}$ Membrane System Technology}

The purpose of this report is to investigate and describe on the cost and performance effectiveness of the SEAMIST ${ }^{\mathrm{TM}}$ membrane and instrumentation emplacement technology by analyzing how it compares to existing methods designed to accomplish the same task or set of tasks. In this analysis, we attempt to describe SEAMIST $^{\text {TM }}$ in a sufficient number of different scenarios in order to adequately demonstrate the breadth of its capabilities. Each scenario emphasizes a different function or addresses a different need of the environmental remediation objectives of the Department of Energy. Because of the diversity of capabilities of this new technology, each scenario must use a different conventional technology as a baseline of comparison.

SEAMIST TM is an innovative technology with many attributes:

- SEAMISTTM $^{\mathrm{TM}}$ an innovative technology that can facilitate measurements of soil-borne contaminants in horizontal and vertical boreholes

- SEAMIST $^{\mathrm{TM}}$ consists of an airtight membrane that is pneumatically emplaced inside the borehole along with any attached sampling or measuring equipment, e.g., sampling ports, absorbent collectors, in situ sensors

- $\quad$ SEAMISTTM can be used to facilitate characterization and monitoring for VOCs, SVOCs, pesticides, her-

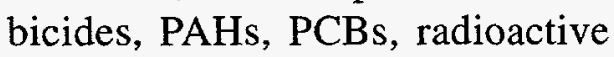
substances, metals, and other soil- or water-borne contaminants

- $\quad$ SEAMIST ${ }^{\mathrm{TM}}$ can also be used as a platform from which to tow in situ instruments such as cameras, neutron logging tools, and sensors through the borehole to obtain real-time data

- SEAMISTTM can be installed permanently with grout, semi-permanently with sand, or on a non-permanent basis by using positive air pressure

- $\quad$ SEAMISTTM can be a substitute for conventional borehole casing, but can also perform some functions that have no simple baseline of comparison, e.g., it can be used in conjunction with absorbent wicking pads to obtain samples of pore fluid contaminants on a recurring basis

- The magnitude of the cost savings possible from using SEAMIST ${ }^{\mathrm{TM}}$ instead of conventional methods increases as the depth of the contamination increases and increases as the variety of contaminants at a site increases

\section{Analysis and Caveats}

This analysis to determine the cost effectiveness of using the innovative SEAMISTTM technology is performed within the context of five scenarios. Each scenario highlights a different characteristic or need for some realistic set of site conditions that the DOE may encounter. Scenario 1 consists of a deep VOC contaminant plume (about $100 \mathrm{ft}$ ) which must be characterized and then monitored. Scenario 2 also involves a VOC contaminant plume; however, this plume is very shallow. Scenario 3 involves contaminants which are not volatile, but which ex- 
ist in the pore fluids of the soil (see bullets). Scenario 4 involves taking moisture measurements to detect leakage under a low-level radioactive land disposal pit. Finally, Scenario 5 represents a combination of the requirements of Scenarios 1 and 3; its purpose is to demonstrate that there is synergism and economies of scope possible which result in additional cost savings over and above those of the separate scenarios.

Successful use of the SEAMIST ${ }^{\mathrm{TM}}$ technology requires that the geology of the site be sufficiently stable so that the borehole does not collapse before the membrane is emplaced. Also, the borehole surface must not be so rocky or sharp that it will tear the membrane.

\section{Cost Drivers}

The cost drivers for both the new and the selected baseline technologies depend on the specific scenario. For the deep VOCs of Scenario 1, the SEAMIST ${ }^{\mathrm{TM}}$ system consists of vapor monitoring ports fabricated into the membrane. The baseline in Scenario 1 was chosen to be vapor monitoring ports constructed in conventional PVC casing. Both systems have tubing that carries the local VOC vapors to the surface for sampling and analysis. The cost drivers for Scenario 1 are the cost of the membrane for SEAMIST ${ }^{\mathrm{TM}}$ and the cost of the labor to construct the port system for the baseline.

Scenario 2 deals with shallow VOC contamination. The SEAMIST ${ }^{\text {TM }}$ technology in Scenario 2 requires horizontal boreholes, whereas the baseline in this scenario consists of shallow, implanted soil vapor probes. Again, the cost of the fabricated membrane is a major cost to the new technology; however, that cost is far exceeded by the cost to drill the required horizontal boreholes. In this scenario, the new technology is not more cost effective; it is far more economical for shallow VOC contamination to use a system of soil vapor probes. It is worth not- ing, however, that for situations in which the contamination is not accessible from directly above the surface (e.g., across waterways or under buildings) horizontal boreholes and SEAMIST $^{\mathrm{TM}}$ may be the only alternative.

Scenario 3 involves obtaining pore fluid from the vadose zone to analyze for water-borne contaminants such as nonvolatile organic compounds, PCBs, PAHs, pesticides, metals, and even tritium. The SEAMIST ${ }^{\mathrm{rM}}$ setup consists of absorbent wicking pads attached to the side of the membrane which are in direct contact with the borehole soil. The baseline of comparison is a series of vertically stacked, analogously placed, pressure-vacuum suction lysimeters. It is important to note that in this scenario, sampling for contaminants differs between the two alternatives. The cost drivers in this scenario for the SEAMIST ${ }^{\mathrm{TM}}$ setup are the membrane and the cost of drilling the boreholes. For the baseline, the principal costs are the lysimeters, the lysimeter installation, tubing, and in particular, the cost to sample the lysimeters for pore fluid.

Scenario 4 involves the use of a neutron logging tool to obtain measurements of soil moisture under a low-level radioactive land disposal pit. Four horizontal boreholes are drilled underneath the land disposal pit. A SEAMIST TM liner is everted in the borehole as the neutron logging tool is simultaneously towed through it while taking neutron attenuation measurements at 5-ft intervals. The baseline consists of permanently casing the boreholes with aluminum and similarly towing the logging tool using a pulley system. The cost of the conventional aluminum casing is far more than that of the SEAMISTTM liner.

The final scenario represents a combination of the sampling requirements of Scenarios 1 and 3. The purpose of Scenario 5 is to demonstrate the economies of scope that can be achieved with 
SEAMISTTM that are not possible with most conventional technologies. The combination of vapor sampling ports and absorbent wicking pads in one membrane produces additional savings over the sum of the two separate SEAMIST ${ }^{\mathrm{TM}}$ system costs. When the two sets of requirements are combined, the separate sampling systems can be combined into one membrane. Both sampling systems can not be combined for the baseline. This integration capability is by far the most advantageous cost and performance advantage of SEAMIST TM.

\section{Cost Savings}

The cost effectiveness of using this new technology was calculated for each scenario. The cost data used to calculate the cost effectiveness were based on actual costs or stated prices from vendors or on a combination of both. Therefore, no uncertainties were considered for these scenarios. The results are summarized in the table. For detailed information regarding cost estimates, see Henriksen and Booth, 1993.

Overall, SEAMISTTM was shown to be more

Table: A Study of the Cost Effectiveness Scenarios

\begin{tabular}{|c|c|c|c|}
\hline Scen. & System Description & Cost Savings & Cost Equivalencies \\
\hline 1 & $\begin{array}{l}\text { Twelve } 100 \text {-ft vertical bore- } \\
\text { holes each with } 10 \text { VOC } \\
\text { sampling ports }\end{array}$ & $\begin{array}{l}\text { SEAMIST TM can save } 56 \% \\
\text { over the use of conventional } \\
\text { casing equipped with similar } \\
\text { vapor monitoring ports }\end{array}$ & $\begin{array}{l}10 \text { vapor monitoring ports } \\
\text { can be fabricated in a } \\
\text { SEAMIST membrane for } \\
\text { every } 3.5 \text { ports in the } \\
\text { conventional casing }\end{array}$ \\
\hline$\overline{2}$ & $\begin{array}{l}\text { SEAMIST }{ }^{\text {sMstem con- }} \\
\text { sists of four long horizontal } \\
\text { boreholes with vapor } \\
\text { monitoring ports; baseline is } \\
\text { analogous system of soil } \\
\text { vapor probes }\end{array}$ & $\begin{array}{l}\text { New technology is not cost } \\
\text { effective in this case. } \\
\text { However, new technology } \\
\text { may be only alternative in } \\
\text { some cases }\end{array}$ & \\
\hline$\overline{3}$ & $\begin{array}{l}\text { SEAMISTTM system con- } \\
\text { sists of } 10 \text { absorbent } \\
\text { wicking pads in each of } \\
\text { twelve } 100-\mathrm{ft} \text { vertical } \\
\text { boreholes; baseline is } \\
\text { system of pressure-suction } \\
\text { lysimeters placed in corres- } \\
\text { ponding locations }\end{array}$ & $\begin{array}{l}\text { Baseline is three times more } \\
\text { costly to use. Both systems } \\
\text { yield same information. } \\
\text { There are substantial perfor- } \\
\text { mance differences between } \\
\text { systems }\end{array}$ & $\begin{array}{l}\text { For every ten SEAMISTTM } \\
\text { absorbent pads can be } \\
\text { installed and sampled, only } \\
2.3 \text { lysimeters can be } \\
\text { installed and sampled. }\end{array}$ \\
\hline 4 & $\begin{array}{l}\text { Four horizontal boreholes } \\
\text { are drilled under a } \\
\text { radioactive land disposal pit } \\
\text { to facilitate moisture } \\
\text { measurements. A neutron } \\
\text { logging tool is towed } \\
\text { through the borehole while } \\
\text { taking measurements every } \\
\text { five ft }\end{array}$ & $\begin{array}{l}\text { The total scenario cost using } \\
\text { SEAMISTT is } 16 \% \text { less } \\
\text { than the total scenario cost } \\
\text { using conventional casing. } \\
\text { The significant cost savings } \\
\text { due to using SEAMISTM is } \\
\text { not obvious because the cost } \\
\text { of the borehole liner is } \\
\text { overshadowed by the large } \\
\text { cost to actually drill the } \\
\text { boreholes. For existing } \\
\text { bore o o les, us ing } \\
\text { SEAMIST } \\
\text { than conventional casing }\end{array}$ & $\begin{array}{l}\text { For every one conventional } \\
\text { casing that can be purchased } \\
\text { and installed, ten SEA- } \\
\text { MIST TM liners can be } \\
\text { purchased and installed and } \\
\text { disposed of }\end{array}$ \\
\hline 5 & $\begin{array}{l}\text { Combination of the require- } \\
\text { ments of Scenarios } 1 \text { and } 3 \text { : } \\
\text { sampling for both VOCs and } \\
\text { pore-fluid contaminants }\end{array}$ & $\begin{array}{l}\text { When the requirements of } \\
\text { Scenarios } 1 \text { and } 3 \text { are } \\
\text { combined, there is an } \\
\text { additional cost savings of } \\
27 \% \text { over the sum of the } \\
\text { two separate scenarios. } \\
\text { This additional cost savings } \\
\text { means that SEAMIST }{ }^{\text {TM can }} \\
\text { save a total of } 74 \% \text { over the } \\
\text { sum of the costs of the } \\
\text { baseline technologies }\end{array}$ & See Scenarios 1 and 3 \\
\hline
\end{tabular}


cost effective the deeper the contamination and the greater the variety of contaminant substances. SEAMIST ${ }^{\mathrm{TM}}$ can often be configured to perform tasks that require two different conventional technologies. This introduces economies of scope which can result in significant cost savings.

SEAMISTTM is very easy to remove and to dispose of after use. This is in contrast to conventional casing, which can only be abandoned after costly procedures.

\section{Ongoing Developments}

New, stronger fabric materials are continually being developed for use as SEAMISTTM membranes. Additional innovative uses for SEAMIST ${ }^{\mathrm{TM}}$ include functioning as a conduit liner or straddle packer. SEAMIST ${ }^{\mathrm{TM}}$ has also been used in obtaining gas permeability measurements, for fracture flow mapping, and to measure brine flow.

\section{Conclusions}

- SEAMIST ${ }^{\mathrm{TM}}$ can save from $16 \%$ to $74 \%$ of the cost of using conventional technologies, depending on the application

- SEAMISTTM can sometimes perform tasks for which there is no conventional analog

- In contrast to expensive cased borehole abandonment procedures, discontinuing use of SEAMIST ${ }^{\mathrm{TM}}$ may consist of removing the sand or disconnecting the air flow and then backfilling

\section{References}

A.D. Henriksen and S.R. Booth, "Cost-Effec- tiveness Analysis of the SEAMIST TM Membrane System Technology," Los Alamos National Laboratory document LA-UR-93-3750, October, 1993. 